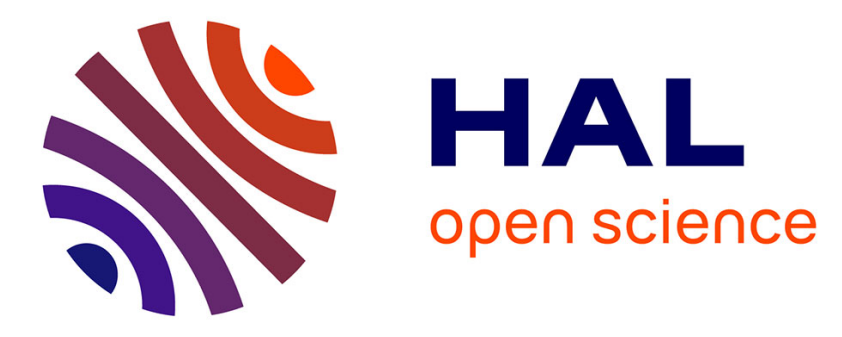

\title{
A chitosan-based nanosystem as pneumococcal vaccine delivery platform
}

Sandra Robla, Maruthi Prasanna, Rubén Varela-Calviño, Cyrille Grandjean, Noemi Csaba

\section{- To cite this version:}

Sandra Robla, Maruthi Prasanna, Rubén Varela-Calviño, Cyrille Grandjean, Noemi Csaba. A chitosan-based nanosystem as pneumococcal vaccine delivery platform. Drug Delivery and Translational Research, 2021, A Perspective of Drug Delivery and Translational Research in Europe, 11 (2), pp.581-597. 10.1007/s13346-021-00928-3 . hal-03313326

\section{HAL Id: hal-03313326 \\ https://hal.science/hal-03313326}

Submitted on 3 Aug 2021

HAL is a multi-disciplinary open access archive for the deposit and dissemination of scientific research documents, whether they are published or not. The documents may come from teaching and research institutions in France or abroad, or from public or private research centers.
L'archive ouverte pluridisciplinaire HAL, est destinée au dépôt et à la diffusion de documents scientifiques de niveau recherche, publiés ou non, émanant des établissements d'enseignement et de recherche français ou étrangers, des laboratoires publics ou privés. 
Sandra Robla, Maruthi Prasanna, Rubén Varela Calviño, Cyrille Grandjean \& Noemi Csaba.

\section{Abstract}

$4 \quad$ Chitosan-based nanosystems have been described as interesting tools for antigen delivery and for enhancing

5 the immunogenicity of nasally administered vaccines. As a possible vaccine delivery method, the chemical

6 conjugation of chitosan nanocapsules with the Streptococcus pneumoniae cell membrane protein PsaA

7 (pneumococcal surface adhesin A) is suggested here. The antigen PsaA, common to all pneumococcus

8 serotypes, is expected to improve its uptake by immune cells and to activate specific T cells, generating an

9 adaptive immune response against pneumococcus.

10 With this aim, chitosan nanocapsules with thiol-maleimide conjugation between the polymer (chitosan) and the antigen (PsaA) were designed to enable the surface presentation of PsaA for immune cell recognition. Spherical shaped particles, with a size of $266 \pm 32 \mathrm{~nm}$, positive charge of $+30 \pm 1 \mathrm{mV}$ and good stability profiles in simulated nasal fluids (up to $24 \mathrm{~h}$ ) were achieved. PsaA association rates were three times higher compared to nanocapsules without covalent polymer-protein conjugation. Cytotoxicity studies in cell culture media showed non-toxic effect under $150 \mu \mathrm{g} / \mathrm{mL}$ concentration of nanocapsules, and subsequent studies on the maturation of immature dendritic cells in the presence of antigen-conjugated nanocapsules displayed peripheral blood mononuclear cell activation and lymphocyte differentiation after their presentation by dendritic cells. Secretion of TNF $\alpha$ following exposure to nanocapsules and the ability of nanocapsules to activate CD4 and CD8 T lymphocytes has also been studied. 


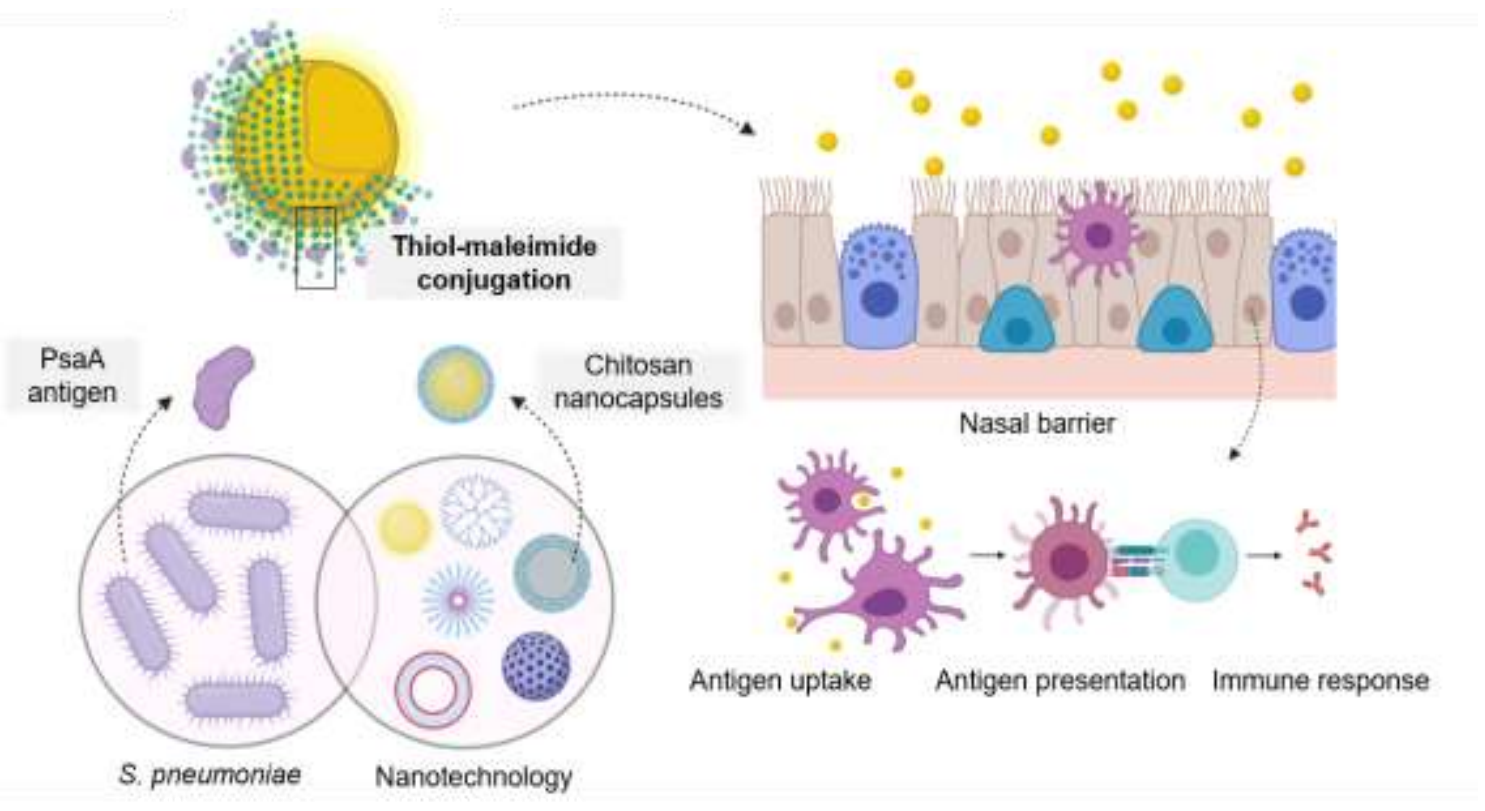

21 Graphical abstract: Antigen loaded nanocarriers uptake and presentation by professional presenting cells.

22 Keywords: Chitosan, nanovaccine, dendritic cell, antigen protein, immune response.

\section{Introduction}

Streptococcus pneumoniae is an opportunistic pathogen that colonizes the human upper respiratory tract and causes pneumonia, meningitis and septicemia [1]. It is responsible for high morbidity and mortality rates, especially among infants, elderly and immunocompromised people [2]. The cell surface of $S$. pneumoniae contains various proteins and capsular polysaccharides (CPS) that play an important role in pathogen attachment and immune system evasion. The CPS diversity results in more than 96 stereotypes whereas cell surface proteins are more conserved and less variable [3]. Currently available CPS-based vaccines such as PCV13 and PCV10 (Pneumococcal Conjugated Vaccines) and PPSV23 (Pneumococcal Polysaccharide Vaccine) only induce specific serotype dependent immune responses [4]. In addition, PPSV23 lacks the ability to generate robust immune responses in high-risk populations such as infants or the elderly. To address some of these obstacles, several studies investigated the possibility of using protein antigens expressed at the $S$. pneumoniae cell wall as potential vaccine candidates. One relevant cell membrane protein is Pneumococcal surface adhesin A (PsaA) [5]. PsaA is a critical factor for the colonization and adhesion of the pneumococcus in nasopharyngeal epithelial cells. It has been shown to activate both the humoral and cellular response of the immune system against the entry of the pathogen via the respiratory airways [6]. 
Intranasal route has been extensively explored for non-invasive immunization, stimulating mucosal and systemic immunity and protecting against respiratory infections [7]. The protective nasal epithelial barrier presents a large surface area which produces a rapid permeation of drugs [8], as well as the NALT (Nasal Associated Lymphoid Tissue), responsible for the production of long-term antigen-specific antibodies [9][10]. The nasal barrier exhibits metabolic activity and is covered with a dynamic mucus layer which limits the permeability of the epithelium and decreases formulation residence time [11]. In this context, nanostructures have been described as interesting tools to enhance the delivery of proteins, improving the immunogenicity of nasally administered vaccines [12]. Indeed, nanostructures play an important role in the stimulation of an adaptive immune response, upon facilitating the antigen uptake and processing by professional antigen-presenting cells such as dendritic cells (DCs) [13], and the immediate innate immune response against these inhaled external substances by macrophages [14]. Chitosan (CS), a polysaccharide derived from the deacetylation of chitin [15] has been widely used in the design of nanocarriers for nasal absorption of peptides like insulin, salmon calcitonin, leuprolide or parathyroid hormone [16], thanks to its high mucoadhesiveness, biocompatibility and biodegradability [17]. Previous studies have shown that chitosan nanocapsules are good candidates for protein administration by nasal route [16], and also have been reported to have an adjuvant effect by promoting innate immune responses [18].In this research, a mucoadhesive chitosan nanocarrier containing a covalently conjugated pneumococcal protein antigen was designed and characterized to evaluate its capacity as a nasal drug delivery system..

\section{Materials and methods}

Miglyol 812® was purchased from Cremer Oleo (Hamburg, Germany), polyethylene glycol stearate 40 (PEG-st 40) was purchased from Croda Chemicals Europe Ltd (Snaith, United Kingdom) and sodium glycocholate (SGC) was obtained from Dextra laboratories Ltd (Reading, United Kingdom). Chitosan HCl $\left(\left(\mathrm{C}_{6} \mathrm{H}_{11} \mathrm{NO}_{4} \mathrm{Cl}\right)_{\mathrm{n}}, \mathrm{Mw}: 1526.5 \mathrm{~g} / \mathrm{mol}\right.$, deacetylation degree of $\left.85 \%\right)$ was purchased from Heppe Medical Chitosan GmbH (Saale, Germany). 1-Ethyl-3-(3-dimethylaminopropyl) carbodiimide hydrochloride (EDC, $\mathrm{C}_{8} \mathrm{H}_{17} \mathrm{~N}_{3}, \mathrm{Mw}$ : $191.7 \mathrm{Da}$ ), $\mathrm{N}$-Hydroxysuccinimide (NHS, $\mathrm{C}_{4} \mathrm{H}_{5} \mathrm{NO}_{3}$, Mw: 115.09 Da), sodium chloride $(\mathrm{NaCl})$, potassium chloride $(\mathrm{KCl})$, calcium chloride hydrate $\left(\mathrm{CaCl}_{2} \cdot 2 \mathrm{H}_{2} \mathrm{O}\right)$ and mucin type III were purchased from Sigma Aldrich (MO, USA). Maleimide propionic acid 95\% (m-PA, $\mathrm{C}_{11} \mathrm{H}_{10} \mathrm{~N}_{2} \mathrm{O}_{6}$, Mw:169.13 Da) and hydroxylamine were obtained from Alfa Aesar (MA, USA). Cyanine5 NHS ester dye (Cy5-NHS) was provided by Lumiprobe (Hannover, Germany), S-acetylthioacetate succinimidyl ester 
(SATA, Mw: 231.23 Da) and the SnakeSkin ${ }^{\mathrm{TM}}$ Dialysis Tubing 3.5K MWCO were obtained from Fischer scientific (MO, USA). The Ni-NTA resin was obtained from Macherey-Nagel, and PsaA used in the experiments was provided by UFIP UMR CNRS 6286 at University of Nantes.

For in vitro experiments sterile and autoclaved material were used. Macrophage Raw 264.7 cell line was obtained from ATCC (VA, USA), Ficoll-Paque ${ }^{\mathrm{TM}}$ PLUS (density $1.077 \mathrm{~g} / \mathrm{mL}$ ) was purchased from GE Healthcare Bio-Science AB (IL, USA), Roswell Park Memorial Institute medium (RPMI-1640) and Dulbecco’s Modified Eagle’s Medium (DMEM) were obtained from GIBCO ${ }^{\circledR}$ (Thermo Fisher Scientific, MA, USA). Granulocyte-macrophage colony-stimulating factor (GM-CSF), interleukin 4 (IL-4), allophycocyanin (APC)-conjugated anti-human CD83 (CD83-APC), phycoerythrin (PE)-conjugated antihuman CD86 (CD86-PE) and fluorescein (FITC)-conjugated anti-human CD1a (CD1a-FITC), were purchased from Miltenyi Biotec (CA, USA), anti-human CD4-APC, CD8-APC; CD25-PE and CD28-PE were obtained from Tonbo Biosciences (CA, USA). Fluorescein (FITC)-conjugated anti-human CD3 (CD3-FITC) and phycoerythrin (PE)-conjugated anti-human Tumor Necrosis Factor alpha (TNF- $\alpha$ ) were both from Miltenyi Biotec (Madrid, Spain). Fetal Bovine Serum (FBS), PSG (100 U/ml penicillin, 0.1 $\mathrm{mg} / \mathrm{ml}$ streptomycin and $2 \mathrm{mM}$ L-glutamine) and Ebioscience ${ }^{\mathrm{TM}}$ 7-aminoactinomycin D (7-AAD) viability staining were purchased from Invitrogen (CA, USA). Lipopolysaccharide (LPS) from Escherichia coli and Brefeldin A (BFA) were purchased from Sigma Aldrich (MO, USA). MTS (reactive de Owen (3-(4,5dinetiltiazol-2-il)-5(3-carboximetoxifenil)-2-(4-sulfofenil)-2H tetrazolium) cell proliferation assay kit was provided by BioVision (CA, USA). Triton ${ }^{\circledR}$ X-100 was purchased from Scharlab (Barcelona, Spain), and interferon gamma (IFNy) was purchased from Peprotech, (London, UK). All other chemicals were of reagent grade or higher purity.

\subsection{Antigen production and characterization}

The mature PsaA used as an antigen was previously expressed and purified [19]. Briefly, a plasmid encoding PsaA deprived of its signal peptide was transformed into E. coli BL 21 cells. Fractions containing the target protein were purified by affinity chromatography and the protein was purified to eliminate any traces of endotoxin present using endotoxin removal beads.

\subsection{Functionalization of the polymer and proteins and their characterization}

\subsubsection{PsaA-SATA conjugation}


For functionalization of PsaA, $1.35 \mathrm{mg}$ of SATA was incorporated at 45 minute-intervals for 3 times $(0.45$

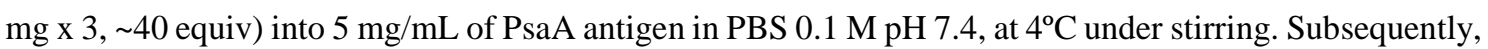
the reaction mixture was dialyzed in $0.1 \mathrm{M}$ PBS to eliminate the excess of reagent using dialysis membrane $(3.5 \mathrm{kDa})$ at $4^{\circ} \mathrm{C}$. The ability of the conjugated protein to retain its structural conformation was studied using circular dichroism (CD) using Jasco J-810 spectropolarimeter. The baseline was obtained using a blank solution containing the buffer. Solution of PsaA or the conjugated PsaA-SATA was diluted to 0.1 $\mathrm{mg} / \mathrm{mL}$ in buffer solution and was scanned over the wavelength range $200-260 \mathrm{~nm}$. The analysis was performed using a 1-nm quartz cylindrical cell at a scanning speed of $50 \mathrm{~nm} / \mathrm{min}, 0.1 \mathrm{~nm}$ bandwidth and a temperature of $20^{\circ} \mathrm{C}$. PsaA and PsaA-SATA mass spectra were also determined on an Autoflex III MALDITOF/TOF spectrometer (Bruker Daltonics).

\subsubsection{Chitosan-maleimide conjugation}

In brief, maleimide-propionic acid (0.553 mg, 5:1 ratio CS:m-PA) in dimethyl sulfoxide (DMSO) was reacted with $5 \mathrm{mg}$ of chitosan in the presence of $0.339 \mathrm{mg}$ of NHS (2:1 ratio CS:NHS) and $0.188 \mathrm{mg}$ of EDC (2:1 ratio CS:EDC) as crosslinkers and were kept under constant stirring for $24 \mathrm{~h}$. Excess reagents were removed by dialysis using dialysis membrane $(3.5 \mathrm{kDa})$. The chemical conjunction between chitosan and maleimide-propionic acid was confirmed by $\mathrm{H}^{1}$-NMR spectrometry (Bruker BRX-500).

\subsection{Preparation of the nanocapsules}

Blank CS and CS-maleimide nanocapsules (NCs) were prepared by solvent displacement technique [20]. An organic phase of $1.6 \mathrm{mg}$ of PEG st-40, $0.5 \mathrm{mg}$ of SGC and $6.25 \mu \mathrm{L}$ of Miglyol ${ }^{\circledR}$ (density $0.94 \mathrm{~g} / \mathrm{mol}$ ) in a final volume of $500 \mu \mathrm{L}$ of ethanol was poured over a $0.5 \mathrm{mg} / \mathrm{mL}$ CS (for CS NCs obtention) or CSmaleimide (for CS-maleimide NCs) solution [21], and was kept under continuous stirring for $1 \mathrm{~h}$. Later, the organic solvent was removed under vacuum using rotary evaporation (R-300 Buchi ${ }^{\circledR}, 150 \mathrm{rpm}, 50 \mathrm{mbar}, 5$ $\min$ at $37^{\circ} \mathrm{C}$ ) to a constant volume of $1 \mathrm{~mL}$. Finally, nanocapsules were isolated by centrifugation (Eppendorf $5430 \mathrm{R}^{\circledR}$, at $20.000 \mathrm{~g}$ for $30 \mathrm{~min}$ at $4^{\circ} \mathrm{C}$ ) and resuspended in ultrapure water.

The association of PsaA and PsaA-SATA was carried out at the end of the synthesis of CS and CSmaleimide nanocapsules, respectively, using a mass ratio of 1:5 (PsaA:polysaccharide) for the association of the protein. In both cases, protein was added and kept under continuous stirring for 10 min, and to ensure the entire removal of unassociated PsaA/PsaA-SATA, nanocapsules were centrifugated (10.000 $\mathrm{g}$ for $5 \mathrm{~min}$ at RT). 
For in vitro studies, the conjugated NCs were labeled with the fluorescent marker Cy5. For this, Cy5-NHS in DMSO was added to CS-maleimide in acetate buffer at pH 5.6 (mass ratio 1:1) and kept overnight under magnetic stirring. Then, the reaction was stopped, and excess dye was removed using PD10 columns (Centri-Pure P10- Gel Fixing Column, Zetadex-emp Biotech GmbH, Berlin, Germany) and the purified product was dialyzed again overnight.

Optionally, NCs were freeze dried in the presence of trehalose $5 \%(\mathrm{w} / \mathrm{v})$ as cryoprotectant. NCs and trehalose solution were mixed $1: 1(\mathrm{v} / \mathrm{v})$ in a freeze-drying glass vials, they were frozen at $-80^{\circ} \mathrm{C}$ and then transferred to the freeze-drier (Labconco Corp., USA), using a primary drying cycle from $-40^{\circ} \mathrm{C}$ to $20^{\circ} \mathrm{C}$ $\left(+10^{\circ} \mathrm{C} /\right.$ step, $18 \mathrm{~h}, 12 \mathrm{~h}, 5 \mathrm{~h}$ and $\left.4 \times 2 \mathrm{~h}\right)$ and a secondary drying cycle $\left(22^{\circ} \mathrm{C}, 3 \mathrm{~h}\right.$ and $-20 \mathrm{mTorr}$ vacuum conditions).

\subsubsection{Physicochemical characterization of nanocapsules}

The hydrodynamic diameter, polydispersity index (PDI) and derived count rate of the prepared NCs were measured using dynamic light scattering (DLS). The zeta potential values were obtained by laser droppler anemometry using a Zetasizer Nano-S (Malvern Instruments; Malvern, UK). The NCs were diluted 1:20 in ultrapure water (MilliQ ${ }^{\circledR}$, Merck, NJ, USA) prior to the measurement. Analysis was performed in triplicate at $25^{\circ} \mathrm{C}$ with a detection angle of $173^{\circ}$ in ultrapure water. Nanoparticle tracking analysis (NTA) was used to measure the particle size of NCs based on imaging after dilution in ultrapure water using a NanoSight NS3000 equipment (Malvern analytical Ltd., Malvern, UK). For NTA analysis CS NCs were diluted 1:100 to keep the concentration within the instrument measuring range.

\subsubsection{Association efficiency}

The association efficiency (AE\%) of protein was estimated by quantifying the difference in absorbance of the total amount of protein and the amount of free protein present in the supernatant after centrifugation. The free protein in the supernatant was analyzed by Micro BCA assay colorimetric method (Micro BCA Protein Assay, Thermofisher Scientific, Spain) using a microplate reader (Synergy H1 Hybrid Multi-Mode, BioTek, Winooski, VT) by measuring the absorbance at $562 \mathrm{~nm}$.

\subsubsection{Morphological characterization} (FESEM Ultra Plus, ZEISS, Germany). For FESEM studies, $10 \mu \mathrm{L}$ of the diluted sample was placed on the 
coated with iridium in an argon atmosphere. For STEM studies, NCs were also diluted 1:100 and $10 \mu \mathrm{L}$ was placed on copper grids with carbon films and then washed drop-by-drop with water. Later the grids were air dried overnight in the desiccator and the analysis was performed.

\subsubsection{Colloidal stability}

The colloidal stability of the antigen loaded nanocapsules before and after freeze drying procedure was studied in vitro using Simulated Nasal Fluid (SNF), composed of $7.45 \mathrm{mg} / \mathrm{ml}$ of $\mathrm{NaCl}, 1.29 \mathrm{mg} / \mathrm{ml} \mathrm{of} \mathrm{KCl}$ and $0.32 \mathrm{mg} / \mathrm{ml}$ of $\mathrm{CaCl}_{2} \cdot 2 \mathrm{H}_{2} \mathrm{O}$ and $\mathrm{pH}$ adjusted at 6.5 . SNF supplemented with mucin type III (1\% sialic acid content) at $0.1 \%$ was also used for the study. For further studies in dendritic cell culture, the stability of the nanosystems was assessed in cell culture RPMI-1640 medium, following the change in particle size, mean count rate and PDI over a period of $24 \mathrm{~h}$. In brief, $20 \mu \mathrm{l}$ of NCs were mixed with $980 \mu \mathrm{L}$ of SNF with $0.1 \%$ mucin or $980 \mu \mathrm{l}$ of RPMI, while nanoparticles suspended in SNF and water at same concentrations are used as controls. The NCs in the different media were shaken at $100 \mathrm{rpm}$ at $37^{\circ} \mathrm{C}$ using a constanttemperature shaker, at different time points $(0,6$ and $24 \mathrm{~h})$ the size and count rate of samples were measured using DLS as described in Section 2.3.1.

\subsection{Release studies}

In vitro release studies of PsaA from the conjugated nanocapsules was performed by incubating nonconjugated CS-PsaA and conjugated CS-maleimide PsaA nanocapsules in a final volume of $1 \mathrm{~mL}$ of SNF in a shaking incubator (Biosan Termo-Shaker TS-100C, $600 \mathrm{rpm}$ at $\left.37^{\circ} \mathrm{C}\right)$. At different time intervals $(1$, $3,5,8,12$ and $24 \mathrm{~h}$ ), samples were centrifuged ( $5 \mathrm{~min}$ at $10,000 \mathrm{~g}$ and $\mathrm{RT}$ ) and $250 \mu \mathrm{L}$ of supernatant were collected for analysis and replaced with fresh SNF medium to maintain sink conditions [22]. The amount PsaA contained in the supernatant at scheduled time intervals were subsequently analyzed by absorbance measurement in a multilabel plate reader using BCA assay at $562 \mathrm{~nm}$.

\subsection{Blood samples and dendritic cell preparation}

Heparinized blood samples were obtained from healthy donors after informed consent. The buffy coats from anonymous donors were donated by the Organ and Blood Donation Agency (ADOS; Santiago de Compostela. Spain). The peripheral blood mononuclear cells (PBMCs) were isolated using Ficoll gradient centrifugation method [23]. Briefly, blood was diluted with PBS (1:1) and layered onto Ficoll-Paque ${ }^{\text {TM }}$ PLUS at a ratio of 2:1 (blood:Ficoll). Different components were isolated after centrifugation (Allegra X12R, Beckman Coulter) at $400 \mathrm{~g}$ for $30 \mathrm{~min}$ at RT, and PBMCs were collected from the interface, washed 
twice with PBS and centrifuged again (300 g, 10 min at RT). Cells were resuspended in $\mathrm{R}_{2}$ medium (RPMI1640 supplemented with $2 \%$ heat-inactivated FBS and $1 \%$ of PSG). The density was adjusted to $1 \times 10^{6}$ cells $/ \mathrm{mL}$ and $10 \mathrm{~mL}$ of cells were seeded into $75 \mathrm{~cm}^{2}$ cell culture flask for $2 \mathrm{~h}\left(37^{\circ} \mathrm{C}, 5 \% \mathrm{CO}_{2}\right)$. After the incubation period, non-adherent cells (peripheral blood lymphocytes or PBLs) were washed with PBS and attached monocytes were cultured for another 6 days, renewing half of the medium after three days, in R10 medium (RPMI-1640 supplemented with 1\% antibiotics and 10\% FBS) in the presence of IL-4 and GMCSF (both at $100 \mathrm{ng} / \mathrm{mL}$ ) to allow the cells to differentiate into DCs [24][25].

\subsection{NCs toxicity on immune cells}

\subsubsection{MTS assay}

The cytocompatibility of the antigen loaded CS-maleimide PsaA NCs with the dendritic cells was studied using MTS assay, and the presence of the soluble formazan product was determined by measuring the absorbance that is directly proportional to the number of viable cells [26]. Monocyte differentiated immature DCs (iDCs) were added into 48 -well microplate $\left(1 \times 10^{6}\right.$ cells $\left./ \mathrm{mL}\right)$ and blank CS-maleimide and CS-maleimide PsaA NCs with a concentration range from $400 \mu \mathrm{g} / \mathrm{ml}$ to $25 \mu \mathrm{g} / \mathrm{ml}$ were incorporated. As a negative control (0\% toxicity), iDCs in culture medium was used, whereas, for the positive control (100\% toxicity), iDCs were incubated with Triton X-100 (0.5\%). In the same manner, macrophage Raw 264.7 cells were incubated with blank CS-maleimide and CS-maleimide PsaA NCs and treated using the same procedure as iDCs. After 4 and $24 \mathrm{~h}$ of incubation under standard sterile conditions for cell culture $\left(37^{\circ} \mathrm{C}\right.$ and 5\% $\mathrm{CO}_{2}$ ), cells were collected and centrifuged (Microfuge 5427-R, Eppendorf, $500 \mathrm{~g}$, $5 \mathrm{~min}$ at RT) for the removal of un interacted nanocapsules. Finally, the cells were incubated with $10 \mu \mathrm{L}$ of MTS reagent and the absorbance was measured at $490 \mathrm{~nm}$ using a microplate reader.

\subsubsection{7-AAD assay}

Cytotoxicity studies on the dendritic cells were also carried out using the intercalative DNA fluorescent dye 7-AAD. iDCs were incubated for $24 \mathrm{~h}$ with different CS-maleimide PsaA NCs concentrations from $900 \mu \mathrm{g} / \mathrm{mL}$ to $50 \mu \mathrm{g} / \mathrm{mL}$ and after the incubation period, cells were washed and stained with $0.05 \mu \mathrm{g} / \mu \mathrm{L}$ of 7-ADD $\left(30 \mathrm{~min}\right.$ at $\left.4^{\circ} \mathrm{C}\right)$ for analysis by flow cytometry (BD FACSCalibur ${ }^{\mathrm{TM}}$, Becton Dickinson). The emission of 7-AAD was detected in the FL-3 channel at $650 \mathrm{~nm}$. The analysis was performed with Flowing software (Cell Imaging Core, Turku Biotechnology Center, Turku, Finland) [27].

\subsection{Interaction of NCs with immune cells}


The analysis of the uptake of CS-maleimide PsaA NCs by the DCs and Raw 264.7 cells was processed by means of confocal laser scanning microscopy (CLSM) and FESEM microscopy, respectively. For CLSM, DCs were incubated with Cy5-labeled nanosystems at a concentration of $150 \mu \mathrm{g} / \mathrm{ml}$ and they were visualized by confocal microscopy (Leica SP5, Mannheim, Germany) after 24 h. For FESEM analysis, Raw 264.7 cells were seeded on a poly-L-Lysine coated cellware (Corning Life Sciences, MA, USA) and nanocapsules were added, and allowed to incubate for $24 \mathrm{~h}$. Later, the cells were fixed using $4 \%$ paraformaldehyde (PFA), washed and gradually dehydrated using increasing ethanol concentrations (30\%, $70 \%, 96 \%, 100 \%$ ). Cells were placed in the desiccator overnight and were sputter coated with iridium before visualization [26].

\subsection{Human DCs phenotype analysis}

iDCs were incubated with the conjugated CS-maleimide PsaA NCs at a final concentration of $150 \mu \mathrm{g} / \mathrm{ml}$ during 48 h. Cells were washed twice (400g, 6 min at RT) to eliminate excess NCs, resuspended in PBS and stained with optimal amounts of different antibodies (CD1a-FITC, CD83-APC and CD86-PE) for 25 min at RT, in the dark. Finally, levels of maturation markers were quantified by flow cytometry.

\subsection{NCs tolerogenic effect in immature DCs}

2,3-Indoleamine dioxygenase (IDO) expression was evaluated in iDCs maturation after conjugated CSmaleimide PsaA NCs exposition. In brief, $1.25 \mu \mathrm{l}$ of L-tryptophan $(100 \mu \mathrm{M})$ was added to the iDCs medium during the last $4 \mathrm{~h}$ of incubation. Then, cells were centrifuged (1,000 g, $5 \mathrm{~min}$ at RT) and supernatants were mixed with $30 \%$ trifluoroacetic acid $(2: 1 \mathrm{v} / \mathrm{v})$ and centrifuged again $(10,000 \mathrm{~g}, 5 \mathrm{~min}$, RT). The supernatant was mixed with the Ehrlich Reagent $(1: 1 \mathrm{v} / \mathrm{v})$ and absorbance at $490 \mathrm{~nm}$ was determined using a microplate reader as indicated.

\subsection{Activation of CD4 and CD8 T cells by NCs}

After total monocyte differentiation into iDCs, they were harvested, resuspended in R10 medium and iDCs $\left(1 \times 10^{6}\right.$ cells $\left./ \mathrm{mL}\right)$ were co-incubated with $150 \mu \mathrm{g} / \mathrm{ml}$ of blank CS-maleimide NCs, CS-maleimide PsaA NCs and PsaA. As a negative control (no activation), iDCs in culture medium were used, whereas for the positive control (total activation), mature DCs (mDCs) were obtained by incubation of iDCs with bacterial LPS (20 $\mathrm{ng} / \mathrm{ml})$ and IFN- $\gamma(200 \mathrm{IU} / \mathrm{ml})$. After $48 \mathrm{~h}$, cells were harvested and centrifuged to remove nanocapsules (300 g, 10 min at RT). In parallel, allogenic PBLs were obtained from buffy coats after 2 h of PBMCs incubation with R2 medium and they were co-incubated with DCs for 12 days, renewing culture media and 
splitting the cells as necessary (usually every 2-3 days). Non-adherent cells were collected and centrifuged ( $500 \mathrm{~g}$ for $5 \mathrm{~min}$ at RT), washed and divided into two different groups. CD4-APCs together with CD25-PE ( $5 \mu \mathrm{L} /$ each) were added to the first, while CD8-APCs together with CD28-PE ( $5 \mu \mathrm{L} /$ each) were added to the latter and left to incubate at $4^{\circ} \mathrm{C}$ for $25 \mathrm{~min}$ in darkness. After incubation, cells were washed and centrifuged (400 g for 6 min at RT) for their analysis by flow cytometry as described above.

\subsection{Cytokine secretion by PBMCs incubated with different NCs}

PBMCs $\left(1 \times 10^{6}\right.$ cells $\left./ \mathrm{mL}\right)$ were collected from healthy donors and incubated with blank CS-maleimide NCs, CS-maleimide PsaA NCs and PsaA alone $(150 \mu \mathrm{g} / \mathrm{mL})\left(5 \% \mathrm{CO}_{2}, 37{ }^{\circ} \mathrm{C}\right)$ for $2 \mathrm{~h}$. After that, cells were washed and centrifuged ( $300 \mathrm{~g}$ for $10 \mathrm{~min}$ at RT), thus removing the nanocapsules. Then, BFA $(10 \mathrm{mg} / \mathrm{ml}$, $5 \mu \mathrm{L} /$ well) was added to block the secretion of cytokines and kept for overnight incubation. The following day, cells were centrifuged again under the same conditions, the PBMCs surface was stained with CD3FITC (10 $\mu \mathrm{L} /$ well) antibody and left for $15 \mathrm{~min}$ at $4^{\circ} \mathrm{C}$ in darkness. Cells were washed, centrifuged $(400 \mathrm{~g}$, 6 min at RT) and fixed with 1\% PFA under constant agitation to avoid cell aggregation, and were incubated again for 15 min in darkness. Cell membrane was permeabilized with $1 \%$ saponin and centrifuged again under the initial conditions for an intercellular staining with TNF $\alpha$-PE cytokine antibody ( $5 \mu \mathrm{L} /$ well) and incubated for $15 \mathrm{~min}$ at $4^{\circ} \mathrm{C}$ in darkness. Finally, cells were washed twice with $0.1 \%$ saponin buffer and fluorescence signals were measured by flow cytometry as indicated.

\subsection{Statistical analysis}

259 Results were expressed as mean \pm standard deviation (SD) and mean \pm standard error mean (SEM) for dendritic cells studies. Data analyses were carried out using GraphPad Prism v.6.01 software (GraphPad Software Inc., San Diego, CA, USA). Statistical analyses using the 2-way ANOVA test in combination with Dunnett's multiple comparisons test were used to determine the difference between donor groups.

\section{Results and discussion}

\subsection{Functionalization of the polymer and protein and their characterization}

\subsubsection{PsaA-SATA conjugation}

In the search for a serotype-independent pneumococcal vaccine, the use of highly conserved pneumococcal protein antigens has become an attractive alternative to achieve immune response against S. pneumoniae 

increase serotype coverage and immunogenicity of PCV7 by reducing nasopharyngeal carriage [30].

271 In our study, the PsaA was obtained by rDNA technology and subsequently, the free amines present in the

272 lysine amino acids of the PsaA were derivatized to produce a thiolated protein. The functionalization with

273 SATA adds sulfhydryl groups to proteins in a protected form. Thus, PsaA when modified with SATA can

274 be stored for extended time periods and the sulfhydryl groups required for the conjugation reactions will be

275 exposed by treating with the hydroxylamine. Conjugation reaction between the PsaA protein and the SATA

276 group is described in Supplementary Figure 1a. The MALDI-TOF technique (Figure 1a) used to

277 determine the protein molecular weight showed that the purified PsaA had a mass of 34,059 Da, while

278 PsaA-SATA conjugated protein had a mass of 35,683 Da. The difference in the molecular weight between

279 PsaA and PsaA-SATA confirms the successful conjugation of SATA to PsaA antigen in the ratio of 13:1.

280 The presence of multiple sulfhydryl groups on the protein helps its efficient coupling to the nanocapsules.

281 Similarly, Derksen et al., have described the use of protein functionalized with SATA for its surface conjugation to liposomes containing maleimide residues [31]. In addition to this, the sulfhydryl modified proteins were also used to prepare protein-protein conjugate nanoparticles to enhance the immunogenicity of the protein antigens [32]. The conformation of the protein antigen is pivotal in conserving the potential epitopes that are responsible for the immunogenicity [33]. The CD spectra (Figure 1b) revealed no changes in the secondary structural conformation of the PsaA-SATA compared to the existing literature [19]. The PsaA antigen presented negative peaks at 208 and $221 \mathrm{~nm}$, which were also observed in the conjugated cases $[19,34]$. 
a)
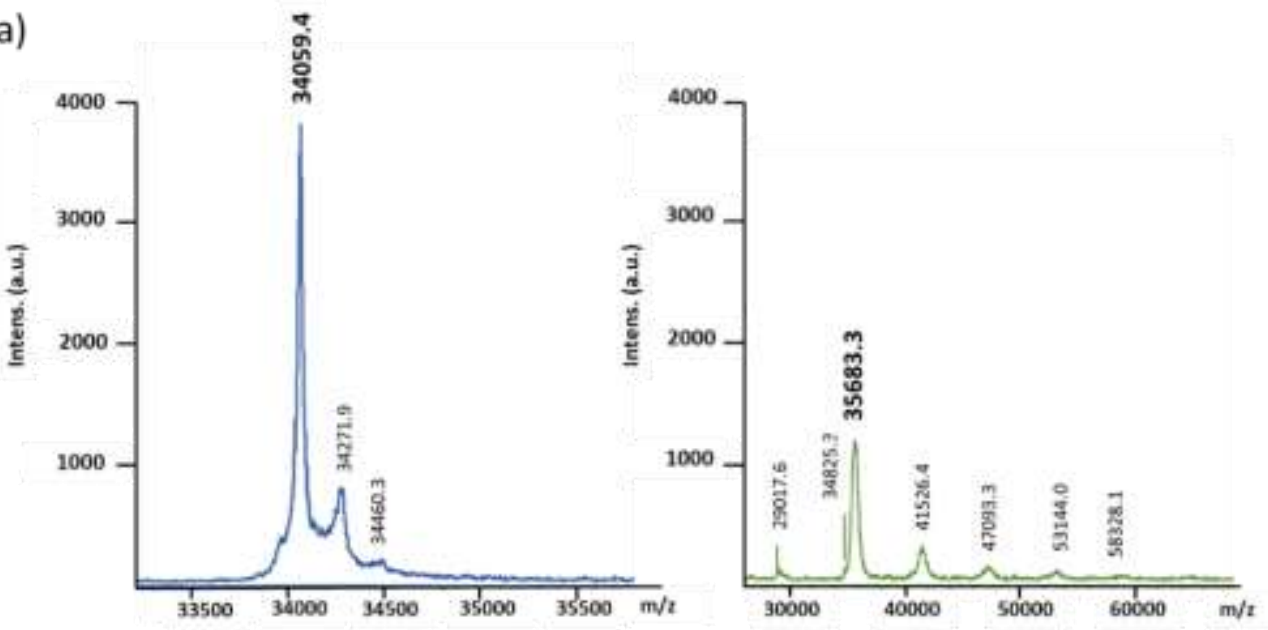

b)

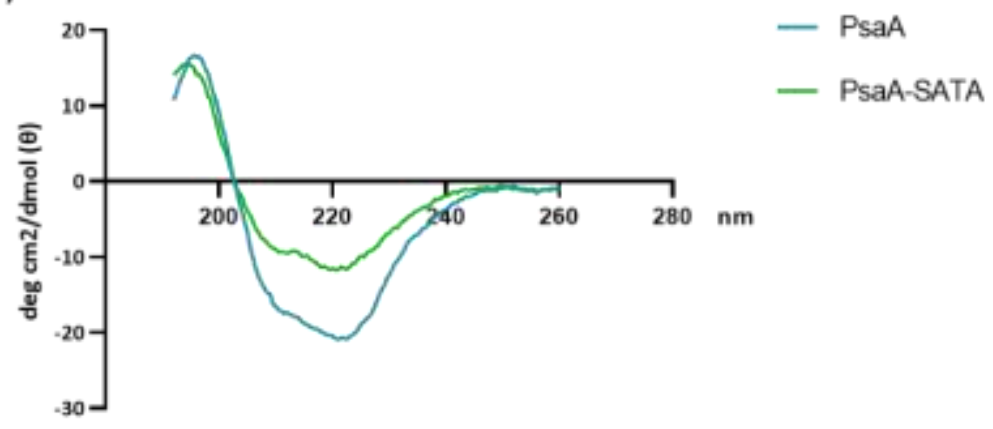

291 Fig. 1: Pre-formulation characterization of PsaA and its conjugate PsaA-SATA: (a) graphs of MALDI-

292 TOF for PsaA (blue line) and PsaA-SATA conjugate (green line). (b) Overlay of CD spectra for PsaA and PsaA-SATA conjugate.

\subsubsection{Chitosan-maleimide conjugation}

Chitosan is an attractive biomaterial with amine groups for conjugation of ligands [35], and previous studies have reported its successful covalent conjugation with maleimide groups [36]. Maleimide selectivity and efficient cross-linking with thiol groups, via Michael addition, has allowed the bioconjugation of chitosan with biomolecules such as peptides [37] or nucleic acids [38], avoiding the generation of reaction byproducts. In the present work, conjugation between CS and maleimide propionic acid was performed and CS and conjugated CS-maleimide samples were freeze-dried and redispersed in deuterium oxide $\left(D_{2} \mathrm{O}\right)$. Conjugation reaction between the polysaccharide and the 3-maleimidopropionic acid group is described in Supplementary Figure 1b. Their $\mathrm{H}^{1}$-NMR spectra had been recorded from 0 to about $10 \mathrm{ppm}$ using a proton NMR spectrometer, to confirm the successful conjugation. The typical CS spectrum was confirmed in Figure 2b, which presented a signal at $\delta \sim 4.9$, corresponding to $\mathrm{H}_{7}$ anomeric proton, the ring proton chemical shift $\left(\mathrm{H}_{2}-\mathrm{H}_{6}\right)$ as overlapping signals at $\delta \sim 3.6-4.0$, which confirmed the presence of the 

of the non-deacetylated part of the polysaccharide was expressed at $\delta \sim 2.1\left(\mathrm{NHCOCH}_{3}\right)$, [39], and deacetylation degree $>85 \%$ could also be confirmed basis of proton integrals. In Figure 2a there still appeared signals similar to that native chitosan signals at $2.1 \mathrm{ppm}\left(\mathrm{NHCOCH}_{3}\right)$, anomeric proton at $2.9 \mathrm{ppm}$ $\left(\mathrm{H}_{1}\right)$ and glucosamide moiety at 3.8-4 ppm $\left(\mathrm{H}_{2}\right.$ to $\left.\mathrm{H}_{6}\right)$ [40]. The presence of new peaks $\mathrm{Hb}$ and $\mathrm{Hc}$ at $\sim 3.5$ and $2.7 \mathrm{ppm}$, respectively, representative of typical protons of the maleimide moiety (Figure 2c), were in accordance with the chitosan chemical modification, proving the successful attachment of chitosan to maleimide propionic acid.

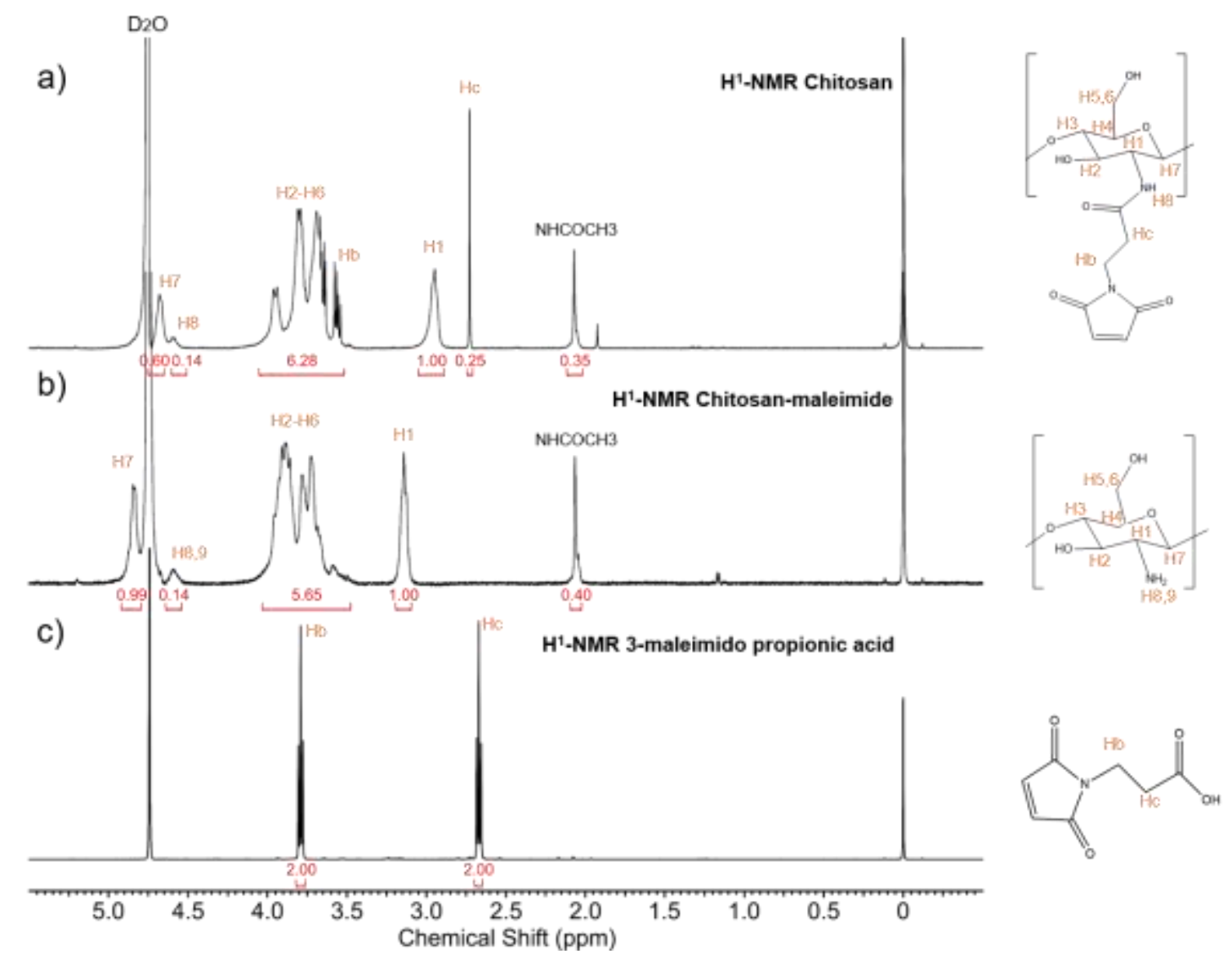

Fig. 2: $\mathrm{H}^{1}$-NMR (400 MHz, $\left.\mathrm{D}_{2} \mathrm{O}\right)$ spectra and integration peaks of Chitosan-maleimide (a), Chitosan (b), 3-maleimidopropionic acid (c), and their respective chemical structures (right). All chemical shifts were expressed as $\delta$ in parts per million (ppm), using the chemical shift of the residual solvent resonances as references $\left(\mathrm{D}_{2} \mathrm{O}: \delta=4.80 \mathrm{ppm}\right)$. 
321 The combination of antigens with adjuvants into an optimal delivery system is a key for the development

322 of a successful vaccine. In addition, aspects such as particle size or surface charge are crucial for the

323 interaction and uptake of particles by immune cells [41]. The delivery carrier was selected based on the

324 knowledge generated by our group and the protein antigen PsaA was associated on the surface of the

325 nanocapsule to obtain a nanovaccine that mimics the pathogen structure and be able to generate a specific

326 immune response.

327 CS NCs are made of a hydrophobic oily core surrounded by a hydrophilic coating. This core-corona structure uses lipids as core components allowing nanocapsules to interact with and penetrate through mucosal surfaces [42]. During the first step, we evaluated different ratios of surfactant:oil (data not shown) and the impact on the particle size and polydispersity of the resulting nanoemulsion (NE), and we selected nanometric size particles with narrow size distribution to form the oily core of the nanocapsules. The amount of Miglyol $^{\circledR}$ was the main variable affecting the size of nanocapsules. Similar results were previously observed for other polymeric nanocapsule compositions such as those described by GonzálezAramundiz et al [21]. The use of non-ionic surfactants such as PEG-st 40 helps in preventing aggregation of particles during the formation of initial NE [43], whilst SGC was used as a co-surfactant that provides negative charge and enhanced stability to the oil core of the NCs [44]. As shown in Figure 3, chitosan molecules were anchored to the surface due to ionic interactions between polymer chains and negatively charged oily core, following an ionic interaction procedure, as previously described for chitosan coating colloidal systems [45], resulting in a core-coated nanostructure.

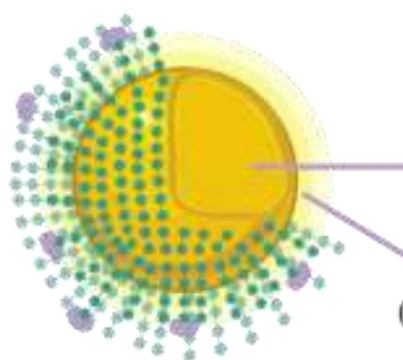

Chitosan PsaA corona

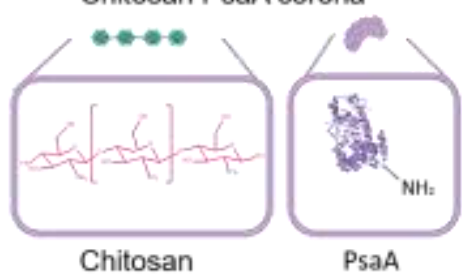
(Mygliol@)

Surfactants (PEGst and Sodium Glycocholate)

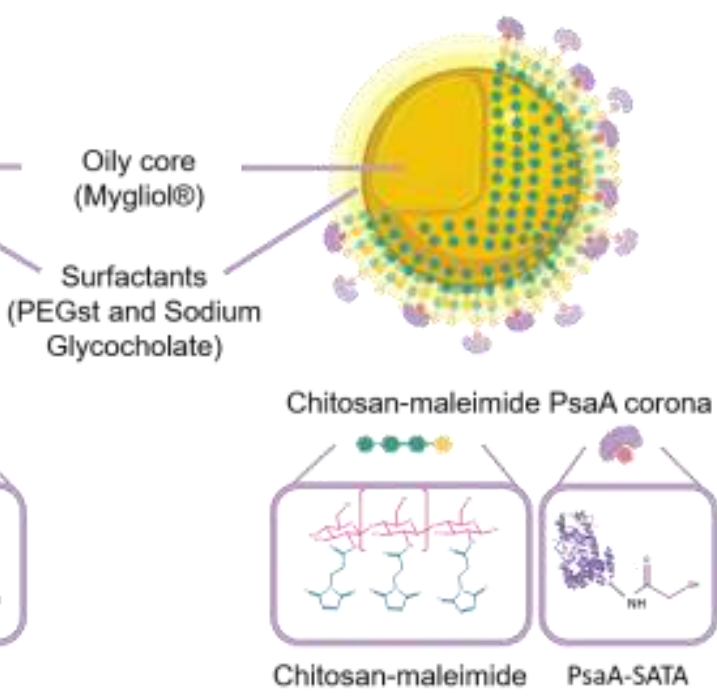


341 Fig. 3: Schematic representation of chitosan polymeric NCs developed in this work. Non-conjugated CS-

342 antigen nanocapsules (left) and CS-antigen nanocapsules after thiol/maleimide conjugation (right). Design

343 was created by Biorender ${ }^{\circledR}$ and ChemDraw ${ }^{\circledR}$ graphics programs.

344 NCs were prepared using the solvent displacement technique. As shown in Table 1, in all cases, they were 345 monodisperse with a size range of $245-266 \mathrm{~nm}$ and the presence of a CS coating surrounding the oily core

346 was corroborated by obtaining a positive surface charge of $+30 \mathrm{mV}$, due to the amine groups in the CS

347 structure. The NCs exhibited an increase in particle size and the surface charge decreased in the presence

348 of antigen when compared with blank CS NCs. This increase in size could be considered as an indicator of 349 a successful binding between the protein and the surface CS of the nanocapsules, and it could also be related 350 to the presence of maleimide-groups as previously described for the development of thiolated-CS liposomes $351[46]$.

\subsection{2. $\quad$ Association efficiency}

Nanoparticle formulations prepared with thiol-maleimide coupling resulted in higher PsaA association efficiency than formulations without this covalent modification. Namely, the association efficiency of protein conjugated to the surface of NCs was approximately 3 times higher with PsaA-SATA compared to ones where the antigen was associated without polymer-protein conjugation reaction (86\% versus $34 \%$, approximately). Covalently conjugated NCs also preserved their particle integrity and physicochemical properties, so that they were expected to improve antigen delivery and activation of APCs, enhancing immunogenicity compared to non-conjugated NCs.

360 For uptake studies, the conjugation of CS-maleimide with Cy5 dye was first performed and nanocapsules were prepared using the same procedure previously described. The incorporation of the fluorophore did not alter the NCs original properties. 


\begin{tabular}{|c|c|c|c|c|c|}
\hline Formulation name & Size (nm) & $\begin{array}{l}\text { Antigen:CS } \\
\text { ratio }\end{array}$ & PDI & $\mathbf{Z}$ potential ( $\mathrm{mV}$ ) & $\begin{array}{l}\text { Association } \\
\text { Efficiency (\%) }\end{array}$ \\
\hline CS NCs & $245 \pm 20$ & - & $<0.1$ & $31 \pm 2$ & - \\
\hline CS PsaA NCs & $248 \pm 21$ & $1: 5$ & $<0.1$ & $29 \pm 2$ & $34 \pm 9$ \\
\hline CS-maleimide NCs & $252 \pm 23$ & - & $<0.1$ & $31 \pm 1$ & - \\
\hline $\begin{array}{l}\text { CS-maleimide } \\
\text { PsaA NCs }\end{array}$ & $266 \pm 32$ & $1: 5$ & $<0.2$ & $30 \pm 1$ & $86 \pm 13$ \\
\hline $\begin{array}{c}\text { CS-maleimide Cy5 } \\
\text { PsaA NCs }\end{array}$ & $254 \pm 16$ & $1: 5$ & $<0.1$ & $29 \pm 1$ & - \\
\hline
\end{tabular}

Table 1: Physicochemical characterization and association efficiency of antigen-conjugated and nonconjugated NCs. Particle size and polydispersity index were obtained by Dynamic Light Scattering. Data represent mean \pm S.D., $\mathrm{n}=8$. CS: Chitosan; NCs: Nanocapsules; PDI: Polydispersity index.

The NTA analysis (Figure 4a) of conjugated CS-maleimide PsaA NCs also confirmed previously reported DLS data showing a particle population of $268 \pm 98.5 \mathrm{~nm}$ (red line), which corresponds to NCs. Analysis of the conjugated CS NCs in solution showed that the concentration/size distribution was less homogeneous than in case of lyophilized NCs, with more than one population of particles. Smaller NCs could be derived of NTA technique, where a higher dilution of CS-maleimide NCs (1:100) might had occasioned their rupture [47], while aggregation of primary NCs into large NCs could be consequence of the decrease of repulsive forces between the particle surfaces after chemical coating modification [48].

374 To assess the stability of conjugated CS-maleimide PsaA NCs after freeze drying process, formulations were lyophilized in the presence of trehalose 5\%. After this procedure, the nanocapsules (purple line) were easily redispersed in ultrapure water and a slight change $(<50 \mathrm{~nm})$ in the particle diameter was observed after NTA analysis. It was also observed that a lower concentration of nanocapsules tended to aggregate after lyophilization procedure compared with NCs in solution, which confirmed trehalose as an appropriate cryoprotectant to prevent nanoparticle aggregation. Production yield calculated by the difference obtained between the initial weight and the weight obtained after lyophilization was $67 \pm 21 \%$. This freeze-dried chitosan nanocarrier could preserve their integrity upon storage without compromising its physicochemical properties, which is a very attractive feature in terms of developing a future thermostable vaccine formulation [49]. 


\subsubsection{Morphological characterization}

385

Different microscopic techniques were used to characterize the conjugated NCs. FESEM and STEM microscopy images revealed a homogeneous population of particles with round-shape structures, which confirm the spherical structure of the NCs. The average particle physical diameter was around $220 \mathrm{~nm}$ that corroborated the hydrodynamic NCs diameter values obtained by DLS, where slightly higher values were influenced by the interactions between the particles and the dispersion media (Fig. 4b and 4c) [50].

a)

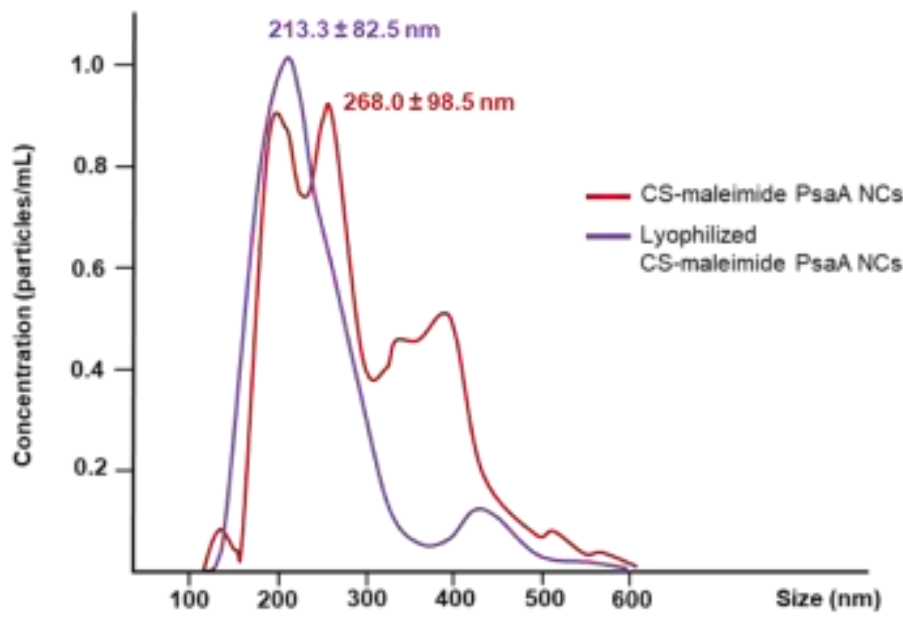

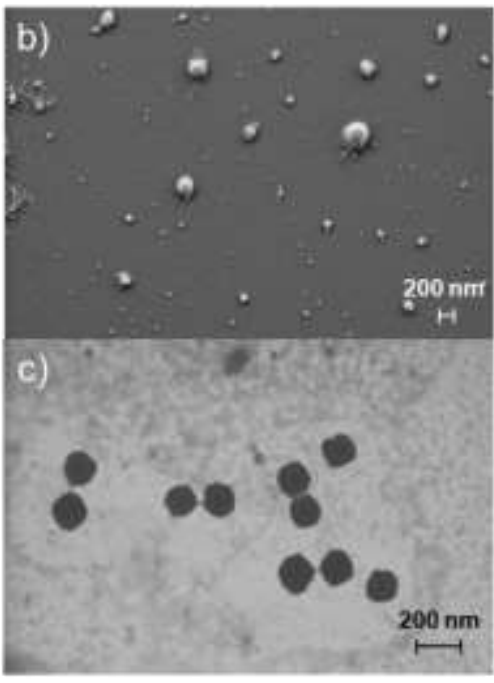

Figure 4: (a) Representative image of the particles size distribution by Nanoparticle Tracking Analysis of conjugated nanocapsules in solution (red line) and conjugated nanocapsules resuspended after lyophilization procedure (purple line), with the mean particle size \pm standard deviation. Electron microscopy scanning (b) and transmission (c) images of conjugated Chitosan-maleimide PsaA NCs. Scale bars are indicated in each image. NCs: Nanocapsules.

\subsection{4. $\quad$ Colloidal stability}

Apart from obtaining adequate physicochemical properties, particle stability must be guaranteed for the developed nanosystems. The understanding of the colloidal stability and aggregation of the nanosystems in the biological media is important for their rational design. Moreover, the nanoparticle aggregation has shown to influence the in vitro cellular responses. Our studies showed that the size of the CS-maleimide PsaA NCs remained unchanged and no signs of aggregation were observed during a period of $24 \mathrm{~h}$ in both RPMI-1640 and SNF in suspension (Figure 5a), and after the freeze-drying process (Figure 5b), which suggest that the NCs were stable in the biological media and could be further proceeded for primary cell culture studies. However, there was a considerable increase in particle size when SNF medium was 
supplemented with mucin type III. This increase in the particle size of the NCs can be attributed to the decrease in the Brownian motion of the particles due to higher viscosity of the medium in the presence of mucin, as well as structural properties of CS such as deacetylation degree or molecular weight [51]. This electrostatic interaction between the positively charged chitosan nanocapsules and the negatively charged mucin molecules yields protein-polysaccharide complexes [52]. According to Feng et al [53], dynamic viscosity could be calculated by DLS method, using water viscosity values $\left(\sim 0.89 \mathrm{cP}\right.$ at $\left.25^{\circ} \mathrm{C}\right)$ and commercial polystyrene latex nanoparticles of known size (Magsphere Inc, USA) as reference. Values of $\sim 1.21 \mathrm{cP}$ for SNF media and $\sim 1.41 \mathrm{cP}$ for SNF media supplemented with mucin type III confirmed this increase in dynamic viscosity. Conjugated CS-maleimide PsaA NCs became larger and their brownian movement slower after incubation in SNF with mucin Type III, which might reflect the mucoadhesive properties of chitosan nanocapsules with mucin macromolecules [54]. Chitosan-mucin interaction by hydrogen and electrostatic bonding has been shown to be suitable for pharmaceutical and biomedical

417 applications in the oral, nasal or ocular routes [55]. However, future in vivo experiments will be needed to confirm the mucoadhesive properties of CS-PsaA nanocapsules conjugated for nasal application. In addition, all formulations have maintained constant stability profiles in aqueous suspension at $4{ }^{\circ} \mathrm{C}$ for at least, 1 month (Supplementary Figure 2). 
a)

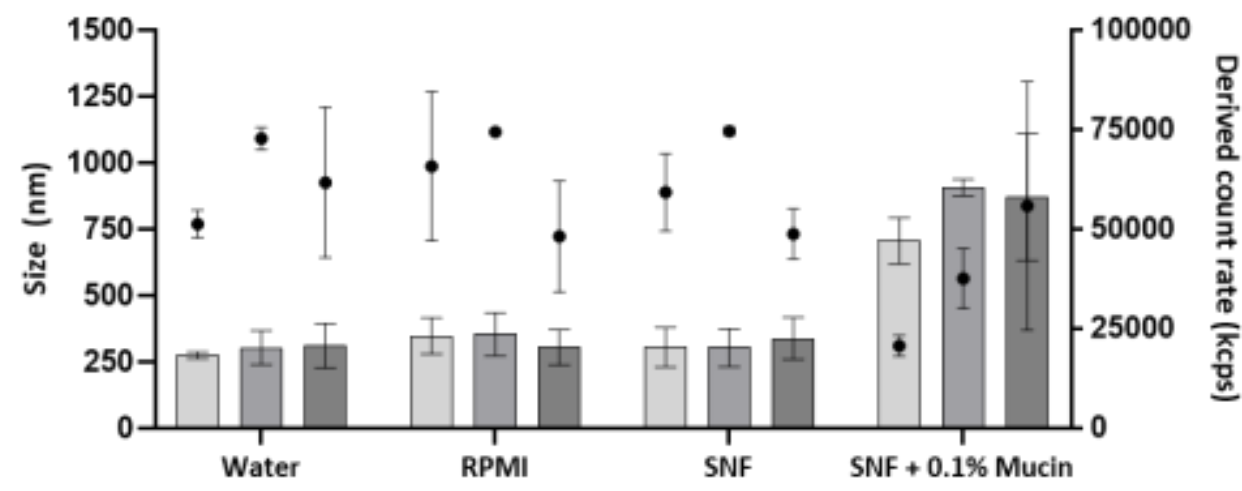

b)

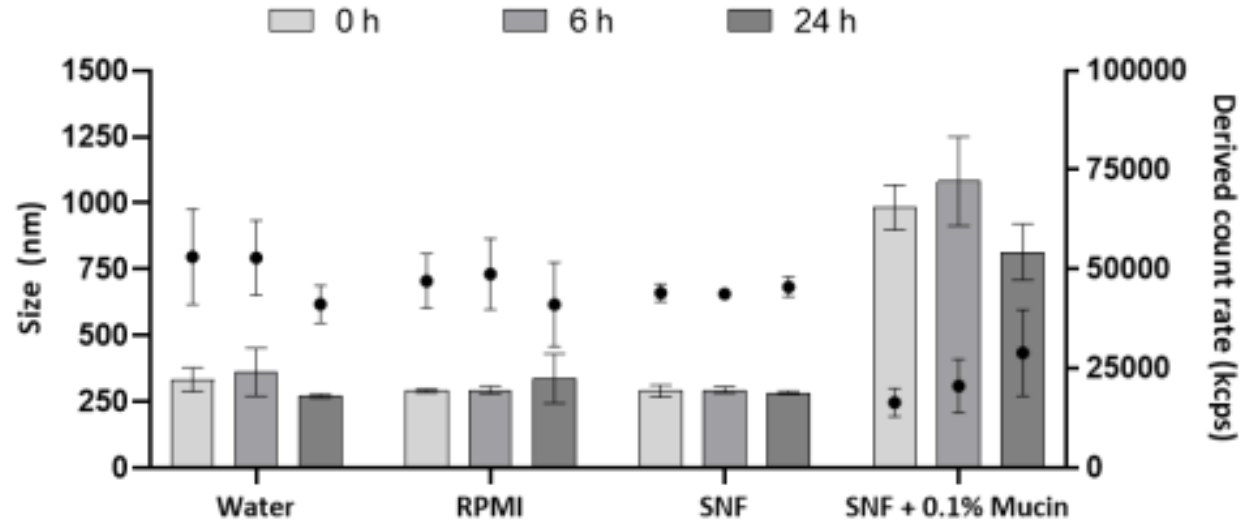

422 Fig. 5: Stability of conjugated CS-maleimide PsaA NCs in suspension (a) and lyophilized (b) conditions 423 in water, cellular media (RPMI), simulated nasal fluid alone (SNF) and with mucine type III (SNF+ 0.1\%

424 Mucin). Bars represent size ( $\mathrm{nm})$, and dots represent derived count rate (kcps) (mean $\pm \mathrm{SD} ; \mathrm{n}=3)$.

425

426

427

\subsection{Release studies}

The in vitro release behavior of PsaA from CS NCs was investigated using simulated nasal fluid (SNF pH =6.5). The accumulative release study of non-conjugated CS-PsaA and conjugated CS-maleimide PsaA NCs was carried out after $24 \mathrm{~h}$ of nanocapsules incubation in SNF by analyzing the total amount of free protein in the media at each time point. Total loading was estimated considering the previously reported association efficiency rates achieved after physical (CS-PsaA NCs) and chemical (CS-maleimide PsaA NCs) conjugation. Values of protein released over time were obtained by extrapolation with a BSA protein concentration range in SNF. As observed in Figure 6, NCs presented an initial fast release during the first 3 hours of approximately the half of the PsaA antigen from the formulations to the medium. The release experiment indicated that the protein was gradually released from the nanocapsules in a time-dependent manner, and that this antigen release remained stable after $8 \mathrm{~h}$. However, a sustained antigen release pattern 

to the CS-maleimide NCs, where the release was slowed down, reaching values over $76 \%$ at $24 \mathrm{~h}$. The relatively slower and sustained release in conjugated CS-maleimide PsaA formulation may be ascribed to the chemical conjugation which produced a stronger interaction between the antigen and the polysaccharide. As showed in similar studies in maleimide-bearing nanogels [56] and maleimidefunctionalized PEGylated liposomes [57], carrier capacity to retain and release the drug was sustained for a prolonged time-period. Overall, both conjugated and free antigen release presented a biphasic profile with a faster initial release followed by a second phase with slow and delayed tendency release profile.

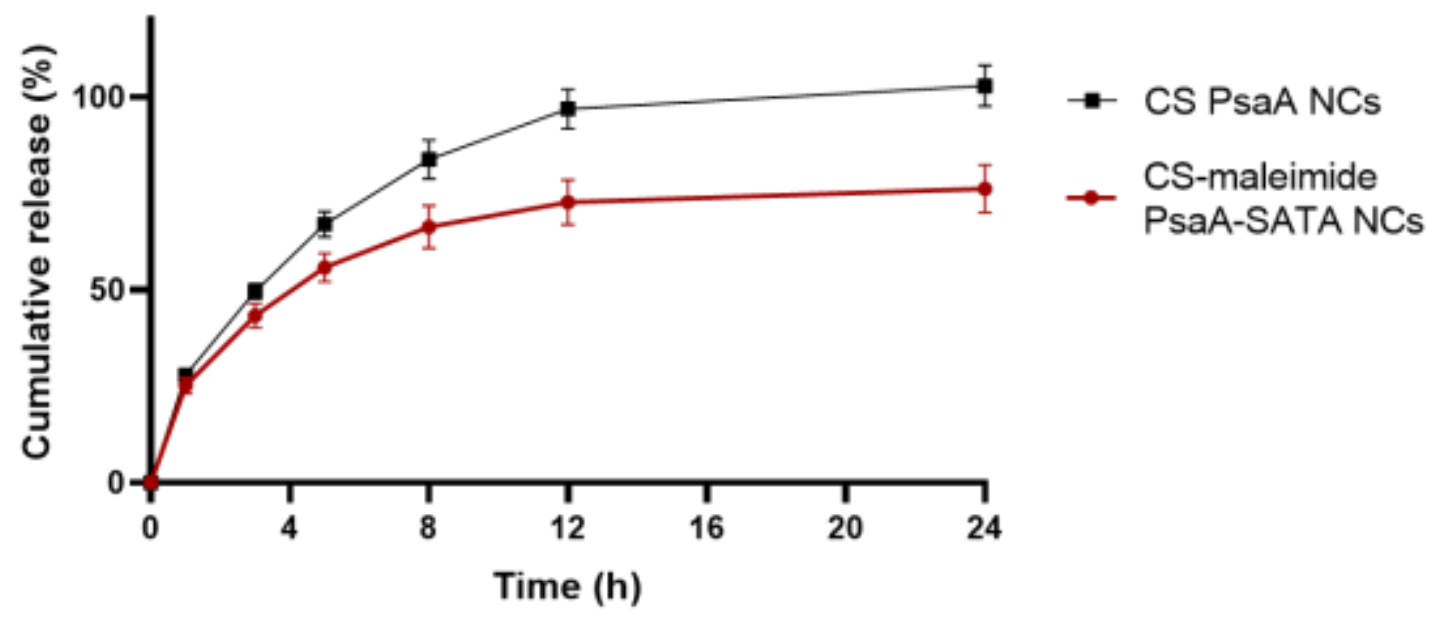

Fig. 6: In vitro cumulative release profile of PsaA antigen from chitosan PsaA and chitosan-maleimide PsaA NCs (mean \pm S.D.; $n=6)$. CS: Chitosan, NCs: Nanocapsules.

\subsection{NCs toxicity on immune cells}

448 To investigate the biocompatibility of both types of conjugated CS-maleimide nanocapsules (blank and antigen loaded), an in vitro MTS assay was performed to study the influence of the nanocapsules on the metabolic activity of macrophages and DCs. Since cationic nanoparticles generally have better electrostatic attractions with the negatively charged cell surface, their toxicity also might increase [58]. After $4 \mathrm{~h}$ (Figure 7a) and $24 \mathrm{~h}$ (Figure 7b) of CS-maleimide and CS-maleimide PsaA NCs incubation with macrophage Raw 264.7 cells, MTS assay showed a significant reduction in cell viability (mitochondrial reductase activity) at concentrations $>200 \mu \mathrm{g} / \mathrm{mL}$. Membrane damage was more pronounced in blank CS-maleimide NCs, being practically total at values of $800 \mu \mathrm{g} / \mathrm{mL}$, while in the case of protein-conjugated nanocapsules it remained around $40 \%$ at higher doses. Similar effects on toxicity were observed after incubation of NCs 

NCs.

459 In a second instance, cell toxicity values were also verified via 7-AAD cytotoxicity assay test at $24 \mathrm{~h}$. Considering that dendritic cells with compromised membranes were stained with 7-AAD, untreated cells were use as control for viable cells. The flow cytometry analyses performed (Supplementary Figure 3) showed a decrease in the number of viable cells as the CS-maleimide PsaA NCs concentration increased, reaching dendritic cell viability values of $65 \%$ at NCs concentrations of $900 \mu \mathrm{g} / \mathrm{mL}$.

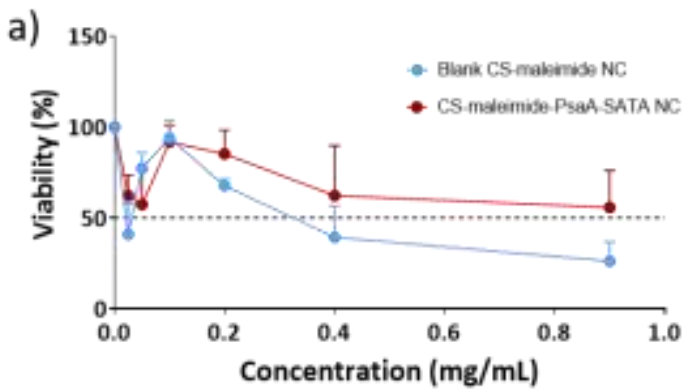

c) 150 b) 150

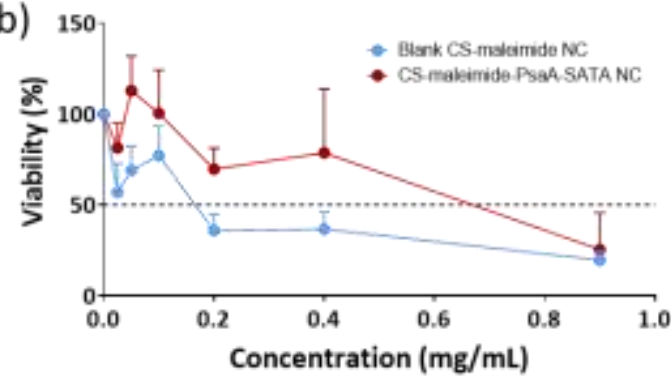

Alink CS makimish NC

- cS-madimido-Psesa-SATA NC

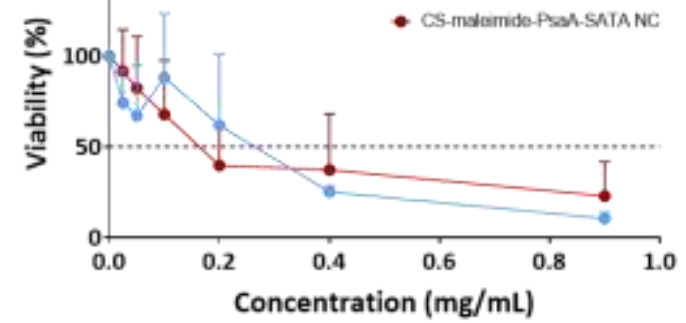

Fig. 7: Effect of CS-maleimide and CS-maleimide PsaA NCs on the viability of Raw 264.7 macrophages (a, b) and immature dendritic cells (c). MTS assay performed on Raw 264.7 cell lines incubated with either CS-maleimide (blue lines) or CS-maleimide PsaA (red lines) NCs using different concentrations of nanocapsules during (a) $4 \mathrm{~h}$ and (b) $24 \mathrm{~h}$. (c) MTS assay performed on iDCs after incubating them with different concentrations of nanocapsules for $24 \mathrm{~h}$. Results were normalized with the percentage of live iDCs incubated in culture media alone and dead iDCs incubated with Triton $(5 \%, 1 \mathrm{x})$ (mean \pm S.D; $\mathrm{n}=4)$. CS: Chitosan; NCs: Nanocapsules.

\subsection{Interaction of NCs with immune cells}

473 Immune cells are able to capture antigens in many different ways, such as phagocytosis, macropinocytosis, or by expressing surface receptors causing endocytosis [59]. Once the antigen has been captured by the antigen presenting cells, it is processed and presented on the cell surface by Major Histocompatibility 
Complex (MHC) [60]. To confirm whether our nanocarriers were able to interact with such immune cells,

477

478

479

480

481

482

483

484

485

486

487

488

489

490

491

492

493

494

we examined the efficacy of CS-maleimide PsaA NCs on antigen uptake in primary cultures of human monocyte-derived iDCs and in the macrophage Raw 264.7 cell line. After incubating the Cy5-labelled NCs (both blank and antigen loaded), the presence of intracellular fluorescence due to the Cy5-labelled NCs confirmed the internalization of the nanocapsules by the DCs. The images obtained from the confocal scanning microscopy confirmed that the nanocapsules (top Figure 8a, red channel) were located within the dendritic cells (bottom, contrast microscope DiC channel) and intracellular distribution of CS-maleimide NCs could be seen throughout the different sections of dendritic cells (also see online video resource in Supplementary material). The physical appearance of DCs could also provide information about their maturation and activation status, for example, by the formation of their characteristic dendrites as seen in our case [25].

On the other hand, the interaction of macrophages with nanocapsules was analyzed by FESEM microscopy. The presence of protrusions on the surface of cells observed in FESEM images (Figure 8c) suggested a possible grouping of nanocapsules and recognition by macrophages.

a)
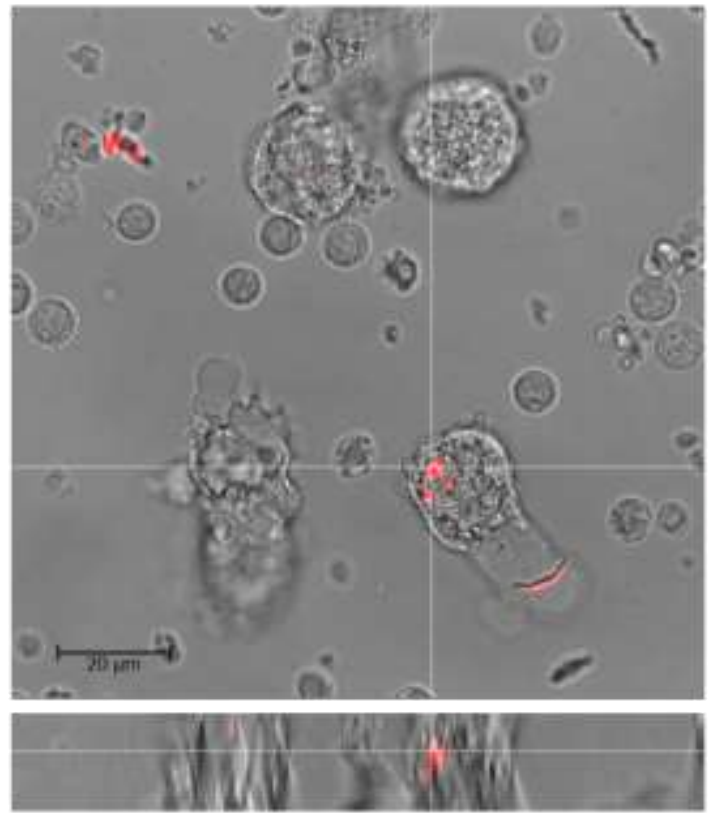

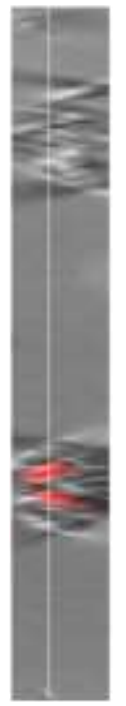

b)

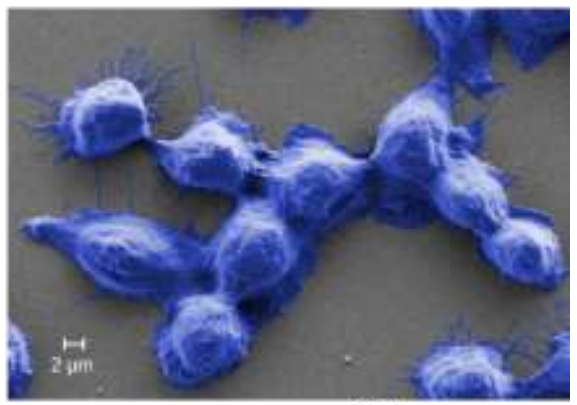

c)

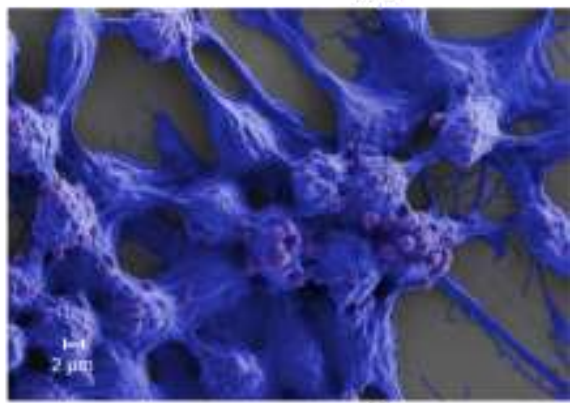

Fig. 8: CLSM images of Cy5-labelled CS-maleimide PsaA NCs incubated with DCs (a) and FESEM images of Raw 264.7 cells alone (b) and after incubation with CS-maleimide PsaA NCs (c). Raw 264.7 cells (blue), and nanocapsules (purple, indicated with white arrows) in (b) and (c) were artificially colored to ease their visualization.

\subsection{Human DCs phenotype analysis}



molecules CD83 and CD86 (indicators of pro-inflammatory activated phenotype in dendritic cells) were analyzed by flow cytometry. The co-stimulatory marker CD86 designates to be a marker primary DCs maturation expressed within first $24 \mathrm{~h}$ and interacts with the CD28 for the $\mathrm{T}$ cell activation, while the increased CD83 is observed in mature/activated DCs. Several studies have proven that antigen delivery to DCs upregulates expression of both CD83 and CD86 that are known to induce T cell receptor signalling and promote T cell activation [61]. In our study, both the blank and antigen loaded CS-maleimide NCs showed an increase in the expression of these maturation markers. The expression of CD83 and CD86

504 (Figure 9a) were 4 folds higher in the case of DCs primed with blank and antigen loaded CS-maleimide NCs when compared to iDCs (MFI=1). However, iDCs treated with PsaA alone displayed a 2 and 3-fold lower expression of CD83 and CD86 markers, respectively. Overall, the results suggest that either the blank or antigen loaded NCs can upregulate the co-stimulatory markers in comparison to the antigen alone.

\subsection{NCs tolerogenic effect on immature DCs}

509 Antigen-presenting cells such as iDCs play an important role in immune regulation, not only as inductors 510 but also inhibitors of an immune response. 2,3-Indoleamine dioxygenase (IDO) is an enzyme involved in 511 tryptophan catabolism, essential for the growth of microorganisms, which regulates T-cell tolerance [62].

512 IDO is a potent immune-suppressive enzyme in macrophages and dendritic cells whose physiological 513 function is to catabolize the essential amino acid tryptophan into the stable metabolite, kynurenine which 514 is known to induce the apoptosis of Th1 cells in vitro [63]. In addition, it is known that the IDO expression 515 by the DCs can greatly impact peripheral tolerance and immune regulation. In this line, we performed a 516 study to evaluate if the NCs formulations were inducing a tolerogenic phenotype on iDCs in terms of T517 cell suppression and tolerance promotion (opposite to a pro-inflammatory response), by quantifying the 518 IDO enzymatic activity after iDCs treatment with NCs. The results obtained from our study showed that 519 the response in the DCs treated with either blank or antigen loaded CS-maleimide NCs signal was similar 520 to one observed in iDCs (Figure 9b), indicating no tolerogenic effect of the NCs. 
521

a)

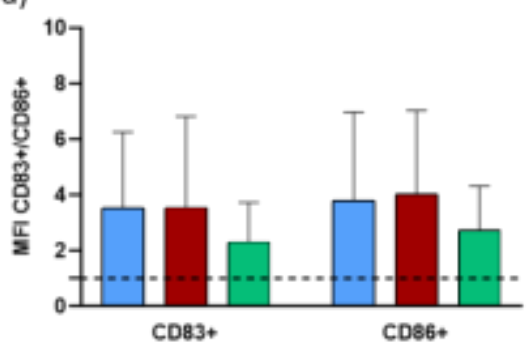

b)

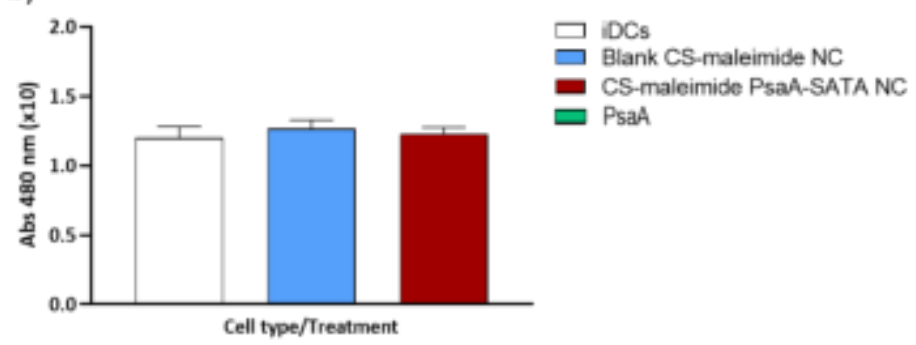

522 Fig. 9: (a) Quantification (\%) of the expression of iDC maturation markers CD83 and CD86. Results are

523

524

525

526

527

528

529

530

531

532

533

534

535

536

537

538

539

540

541

542

543

544

545 expressed as the ratio between the markers mean fluorescence intensity (MFI) in iDCs incubated with the different NCs and the MFI of iDC incubated in culture media alone (MFI=1). The dotted line corresponds to the signal from the iDCs. (b) Indoleamine 2,3-dioxygenase (IDO) activity in dendritic cell cultures. iDCs: immature dendritic cells; CS: Chitosan; NCs: Nanocapsules) (mean \pm SEM; $n=3$ donors).

\subsection{Activation CD4 and CD8 T cells by NCs}

Stimulation of antigen specific CD4+ and CD8+ T lymphocytes is essential for efficient adaptive immunity.

Therefore, we have assessed the ability of the DCs pulsed with antigen, blank CS-maleimide NCs or CSmaleimide PsaA NCs to activate T lymphocytes. The effect of conjugated NCs on the activation of T lymphocytes in an allogenic response was analyzed by flow cytometry. Blank CS-maleimide, CSmaleimide PsaA NCs $(150 \mu \mathrm{g} / \mathrm{mL})$ and PsaA antigen alone were incubated with iDCs and then, the capability of this NC-incubated iDCs to activate allogenic lymphocytes was analyzed quantifying the expression levels of CD25 (for CD4 T lymphocytes) and CD28 (for CD8 T lymphocytes). As shown in Figure 10, mature DCs (mDCs) showed a greater capacity of activating both CD4 and CD8 T lymphocytes (black dots) than iDCs (open dots). On the other hand, preincubation of the iDCs with PsaA protein (green dots), blank CS-maleimide NCs (blue dots), and CS-maleimide PsaA NCs (red dots), induced similar percentages of activated CD4 and CD8 T lymphocytes when compared to iDCs.

In all cases, incubation of iDCs in the presence of NCs caused these APCs to have a similar capacity to stimulate CD4 and CD8 lymphocytes to iDCs, and were lower compared to mDCs. Also, levels of both activated $\mathrm{CD} 4+\mathrm{CD} 25+$ and $\mathrm{CD} 8+\mathrm{CD} 28+\mathrm{CD} 4 \mathrm{~T}$ cells were similar for loaded and non-loaded nanocapsules. However, no significant differences were found between treatments, probably due to donor variability. The similar values between both treatments on the effect of $\mathrm{T}$ cell activation could be a consequence of the composition of the nanocapsules, rather than the presence of the antigen on the surface. [64]. 


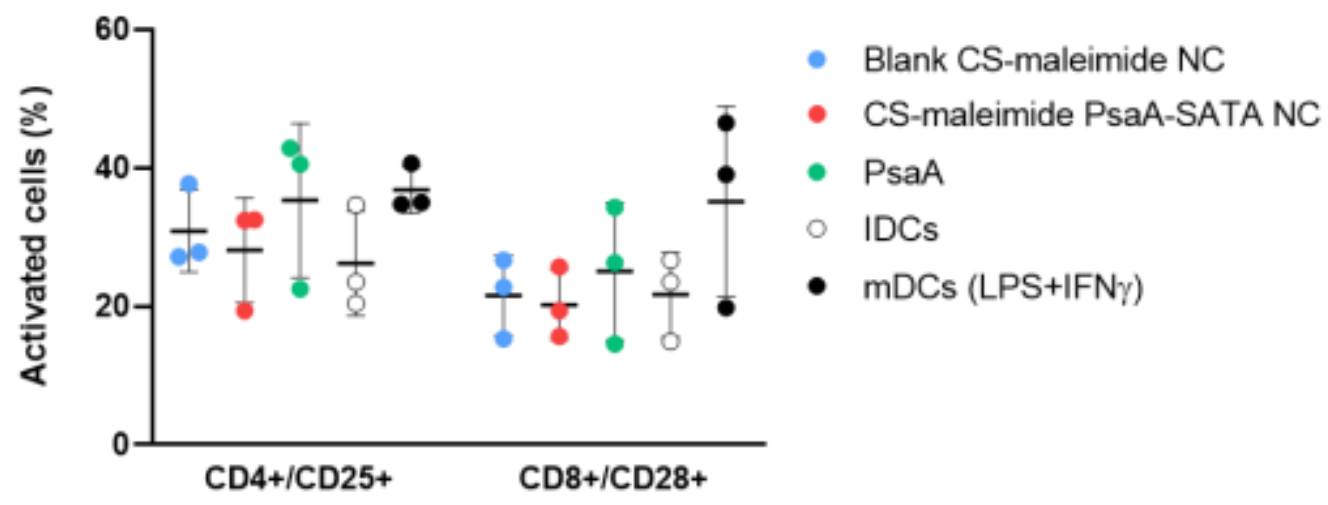

547 Fig. 10: Percentages (\%) of activated T cells after iDCs incubation with formulations. Non-treated iDCs 548 and LPS and IFNy treated iDCs (mDCs) were used as controls (mean \pm SEM; $\mathrm{n}=3$ donors, 2-way ANOVA 549 test). CS: Chitosan; iDCs: immature Dendritic Cells; mDCs: mature Dendritic Cells; NCs: Nanocapsules.

\section{$550 \quad 3.9 . \quad$ Cytokine secretion by PBMCs incubated with different NCs.}

551 In the process of developing a powerful immune response, dendritic cells capture antigens thanks to pattern 552 recognition receptors (PRRs), leading to phenotypic and maturation changes [65]. Depending on the 553 alterations they undergo and the co-stimulation molecules they express, different responses will take place 554 from the T cells (Th1, Th2 or Th17) [66]. The secretion of cytokines by Th1 CD4+ cells (such as IL-2, 555 IFNy, IL-10 or TNF $\alpha$ ) is necessary in order to achieve protection against pneumococcal infection [2]. $556 \mathrm{TNF} \alpha$, secreted by either macrophages, monocytes or activated lymphocytes acts as an inflammatory 557 marker and protects against the infectious pathogens. TNF $\alpha$ production can activate the T cells or can be a 558 product of the activated $\mathrm{T}$ cells. In this procedure, we quantified by intracellular cytokine staining the 559 production of TNF $\alpha$ by $\mathrm{T}$ lymphocytes (CD3+) and non-T cells (CD3-) after incubation with NCs. As can 560 be seen in Figure 11, TNF $\alpha$ production was higher in the CD3- (monocytes) population, being around 5$5618 \%$ compared to CD3+ (lymphocytes) population, where it did not exceed a 5\% in any case. In both cases, 562 a higher percentage of TNF $\alpha$-positive cells was seen after incubated with the different NCs and the PsaA 563 protein compared to iDCs, especially for the CD3+ T cells. Although no statistical differences were found 564 in the different treatments due to the high variability among donors, the obtention of slightly higher cytokine 565 secretion levels in CS-maleimide PsaA NCs could be a consequence of the presence of PsaA attached on their surface. These results were in agreement with previous studies evaluating the effect of cationic CS

567 NCs in inducing inflammatory responses, where cytokine levels were remarkable in one out of three donors tested [67]. Likewise, when the PsaA protein was used, a clear increase in the percentage of TNF $\alpha$-positive 


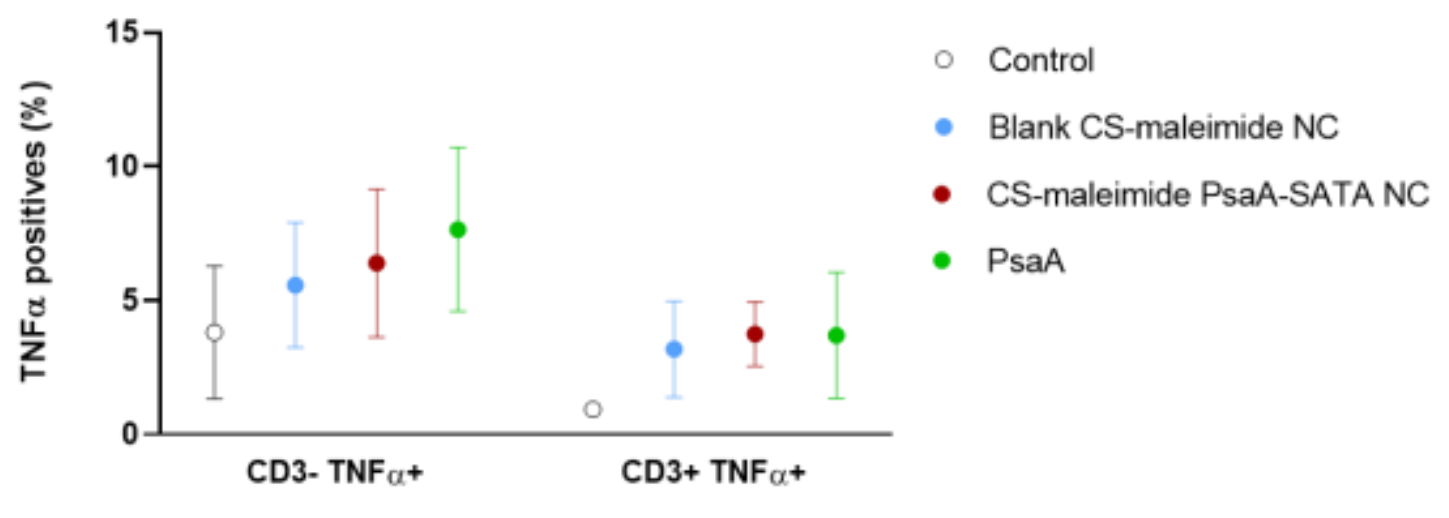

572 Fig. 11: Percentages (\%) of TNF $\alpha$ positive cells (CD3+ and CD3-) after treatment with CS-maleimide NCs, 573 antigen loaded CS-maleimide PsaA NCs and PsaA antigen alone (mean \pm SEM; $n=3$ donors, 2-way 574 ANOVA test). CS: Chitosan; NCs: Nanocapsules.

\section{Conclusion}

576 In the design of targeted nanovaccines towards nasal immune cells, a specific nanocarrier design with 577 mucoadhesive properties is crucial to achieve a higher residence time, avoiding mucociliary clearance and 578 crossing nasal epithelium. In this work, combination of the antigenic protein membrane PsaA together with 579 the high capacity of drug association of chitosan-maleimide modified nanocapsules has been positioned as 580 an interesting perspective for Streptococcus pneumoniae vaccination. Results supported the versatility of 581 non-capsular pneumococcal antigens as vaccine candidates for an efficient mucosal administration. 582 Developed nanocapsules presented a high effective payload of antigen after covalent thiol linkage, 583 mucoadhesiveness together with high physical and biological stability. The nanocapsules capacity to 584 interact with immune cells was conserved and enhanced compared to the free antigen, suggesting them a 585 "green light" future serotype-independent pneumococcal vaccine candidate. To further assess the ability of 586 these nanocapsules as vaccine delivery systems, the evaluation of antigen-specific responses and cytokine 587 profiles is currently under way.

589 This work was supported by ‘Ministerio de Economía y Competitividad' - (RETOS - SAF2016-79230-R - 
591 the Xunta de Galicia (Centro Singular de Investigación de Galicia accreditation 2019-2022) and the

592 European Union (European Regional Development Fund - ERDF), code ED431G 2019/02. Maruthi

593 Prasanna acknowledges his doctoral fellowship from the European Commission, Education, Audiovisual

594 and Culture Executive Agency (EACEA), under the Erasmus Mundus program, "NanoFar: European

595 Doctorate in Nanomedicine and Pharmaceutical Innovation" (Project: 2015-01-C4). The authors have no

596 other relevant affiliations or financial involvement with any organization or entity with a financial interest

597 in or financial conflict with the subject matter or materials discussed in the manuscript apart from those

598 disclosed.

599 Conflicts of interest/Competing interests

600 Authors declare that they have no conflict of interest.

601 Ethics approval

602 All procedures followed were in accordance with the ethical standards of the responsible institutional and

603 national committees on human experimentation and with the Declaration of Helsinki. Informed consent

604 was obtained from all patients for being included in the study.

\section{Consent to participate}

606 All institutional and national guidelines for the obtention and use of human blood were followed. Blood

607 was drawn with the informed consent of all subjects and appropriate permission was obtained from the

608 Institutional Ethics Committee (Comité Etico de Investigación Clínica de Galicia, CEIC).

609 No animal or human studies were carried out by the authors for this article.

\section{Consent for publication}

611 Not applicable

612 Availability of data and material

613 Not applicable

614 Code availability

615 Not applicable 
617 Sandra Robla was in charge of the overall experimental execution, data analysis, writing and figure preparation. Maruthi Prasanna contributed to the experimental execution and writing. Cyrille Grandjean

619 was involved in the synthesis and characterization of the PsaA antigen, reviewing and editing the manuscript. R Varela-Calvino was involved in the design and supervision of the in vitro cell experiments,

621 reviewing and editing the manuscript. Noemi Csaba was involved in writing, reviewing, editing, supervision, project design and administration.

\section{Supplementary material}

(a) PsaA-SATA coniugation.

\section{(a) PSaA-SATA COnjugation.}
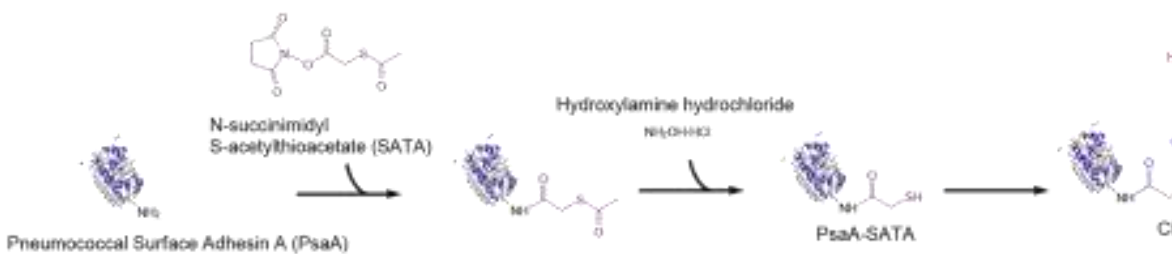

(b) Chitosan-maleimide conjugation
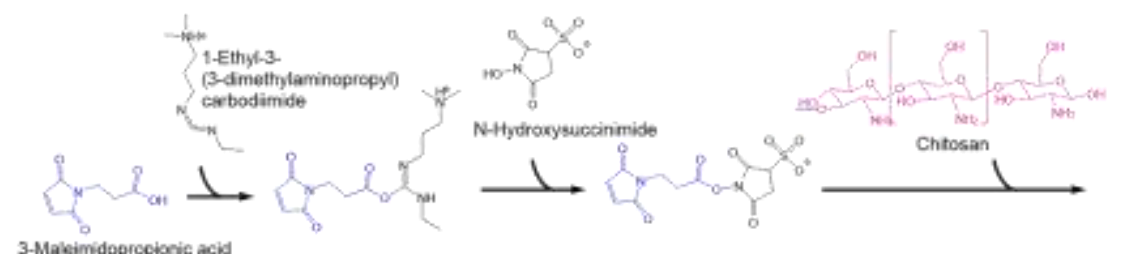

3-Maleimidopropiceric acid

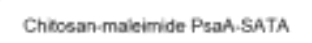

625

Supplementary Figure 1: (a) Chemical conjugation scheme between PsaA and N-succinimidyl Syield after purification and lyophilization procedure was $~ 30 \%$ and $50 \%$, respectively.

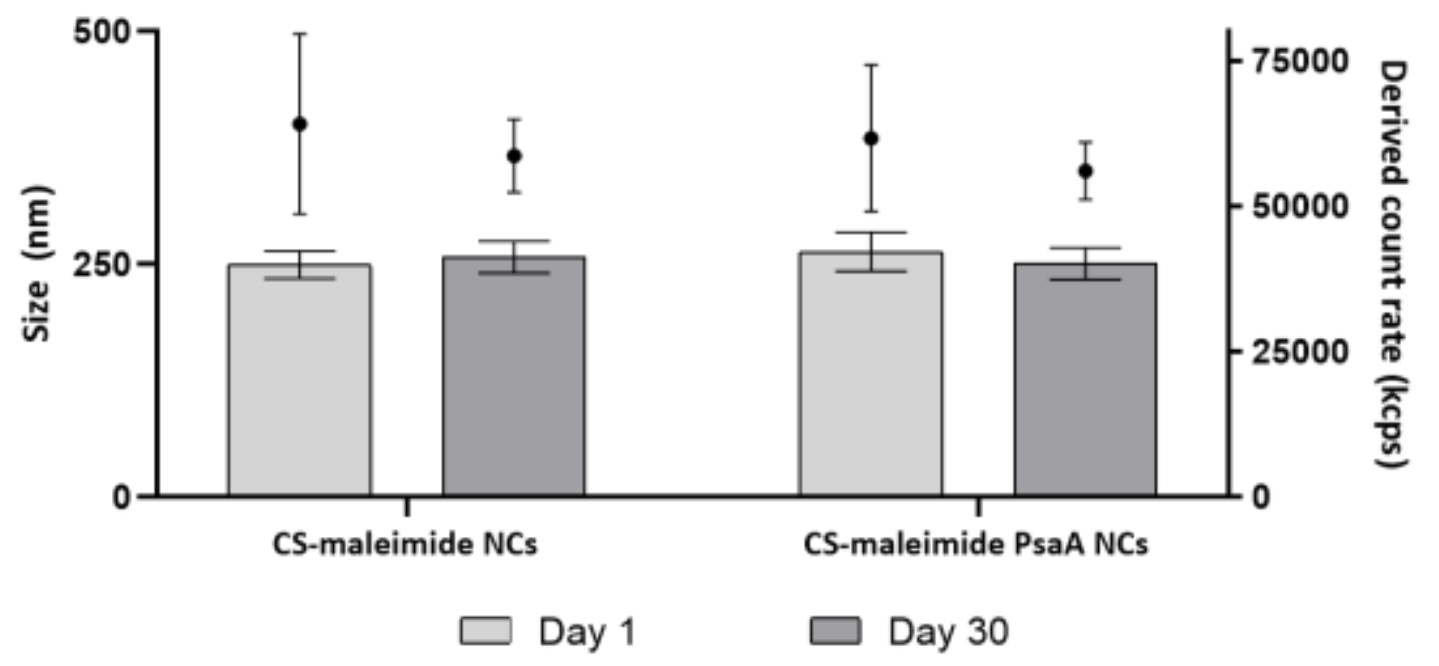




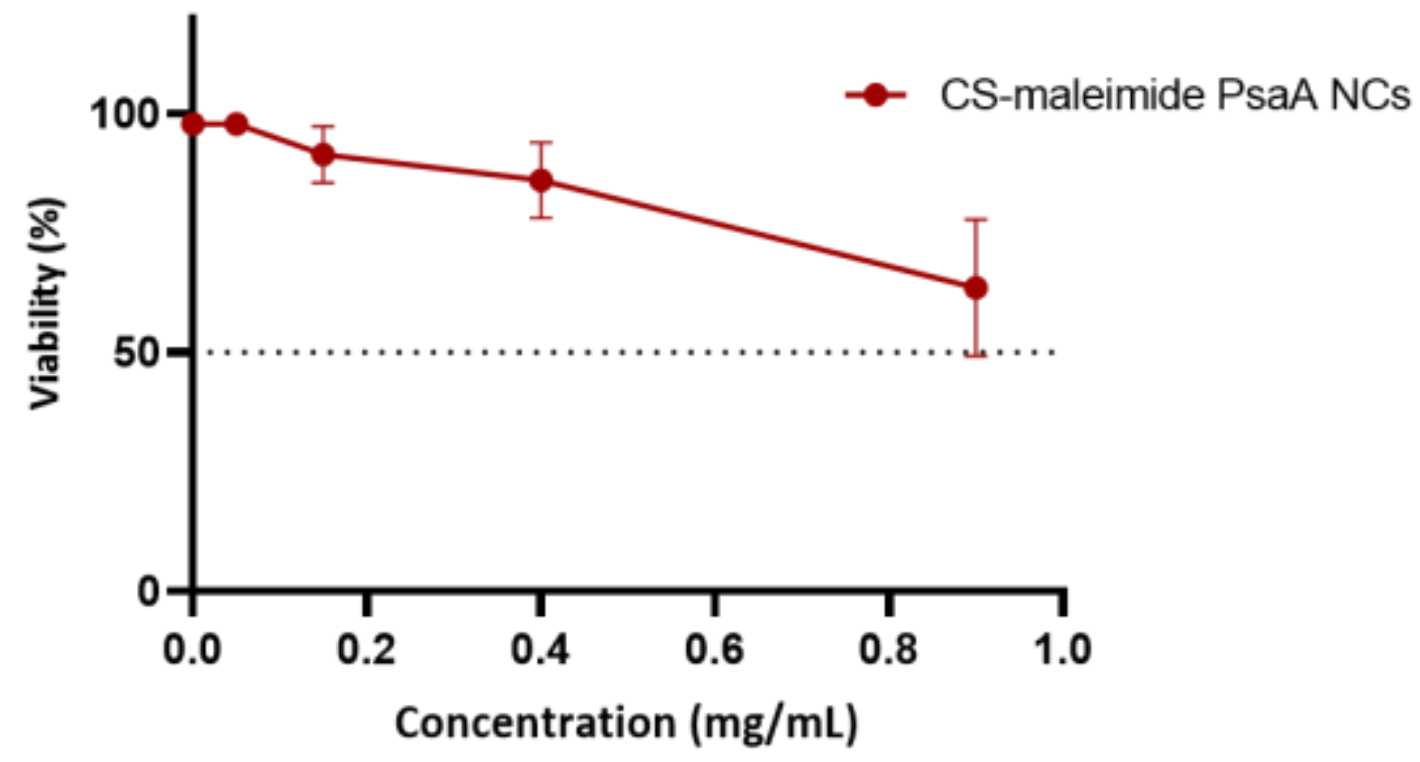

632

633 Supplementary Figure 3: 7-AAD cytotoxicity study in function of the concentration of the conjugated CS-

634 maleimide PsaA NCs. (mean \pm SD; n=3). CS: Chitosan; NCs: Nanocapsules.

635 Online resource 1: Intracellular distribution of Cy5-labelled CS-maleimide PsaA NCs throughout the 636 different sections of DCs after confocal microscopy. 


\section{References}

638 1. Pérez-Dorado I, Galan-Bartual S, Hermoso JA. Pneumococcal surface proteins: When the whole is

639 greater than the sum of its parts. Mol Oral Microbiol. 2012;27:221-45.

640 2. Singh R, Gupta P, Sharma PK, Ades EW, Hollingshead SK, Singh S, et al. Prediction and

641 characterization of helper T-cell epitopes from pneumococcal surface adhesin A. Immunology.

$642 \quad 2014 ; 141: 514-30$.

643 3. Mohammadzadeh M, Mamishi S, Pourakbari B, Mahmoudi S. Recent approaches in whole cell

644 pneumococcal vaccine development : a review study. 2017;9:381-8.

645 4. Leites A, Paula A, Argondizzo C, Esteves S, Jessouron E, Galler R, et al. Cloning and optimization of 646 induction conditions for mature PsaA ( pneumococcal surface adhesin A ) expression in Escherichia coli

647 and recombinant protein stability during long-term storage. Protein Expr Purif. Elsevier Inc.; 2011;78:38-

64847.

649 5. Bartual SG, Alcorlo M, Martínez-Caballero S, Molina R, Hermoso JA. Three-dimensional structures of 650 Lipoproteins from Streptococcus pneumoniae and Staphylococcus aureus. Int J Med Microbiol. Elsevier; $6512017 ; 1-13$.

652 6. Rajam G, Anderton JM, Carlone GM, Sampson JS, Ades EW. Pneumococcal surface adhesin A 653 (PsaA): A review. Crit Rev Microbiol. 2008;34:163-73.

654 7. Zheng Z, Diaz-Arévalo D, Guan H, Zeng M. Noninvasive vaccination against infectious diseases. Hum 655 Vaccines Immunother. 2018;14:1717-33.

656 8. Almeida* AJ, Florindo HF. Chapter 3.1. Nanocarriers Overcoming the Nasal Barriers: Physiological 657 Considerations and Mechanistic Issues. 2012. p. 117-32.

658 9. Calvo P, Remuñan-López C, Vila-Jato JL AM. Chitosan and chitosan/ethylene oxide-propylene oxide 659 block copolymer nanoparticles as novel carriers for proteins and vaccines. Pharm Res.;

660 10. Csaba N, Garcia-Fuentes M, Alonso MJ. Nanoparticles for nasal vaccination. Adv Drug Deliv Rev. 661 Elsevier B.V.; 2009;61:140-57.

662 11. Illum L. Nasal drug delivery - Possibilities, problems and solutions. J Control Release. 2003;87:18766398. 
665 13. Lewis KL, Reizis B. Dendritic cells: Arbiters of immunity and immunological tolerance. Cold Spring 666 Harb Perspect Biol. 2012;4.

667 14. Cole J, Aberdein J, Jubrail J, Dockrell DH. The Role of Macrophages in the Innate Immune Response to Streptococcus pneumoniae and Staphylococcus aureus. Adv Microb Physiol. 1st ed. Elsevier Ltd.; 2014. p. 125-202.

670 15. Prego C, Torres D, Alonso MJ. The potential of chitosan for the oral administration of peptides.

671 Expert Opin Drug Deliv. 2005;2:843-54. 16. Prego C, Torres D, Alonso MJ. Chitosan nanocapsules: A new carrier for nasal peptide delivery. J

673 Drug Deliv Sci Technol. Elsevier Masson SAS; 2006;16:331-7. 17. Kean T, Thanou M. Biodegradation, biodistribution and toxicity of chitosan. Adv Drug Deliv Rev. Elsevier B.V.; 2010;62:3-11. targeting dendritic cells with tumor cell lysate-loaded chitosan nanoparticles vaccine. Biomaterials. Elsevier Ltd; 2017;113:191-202. glycoconjugate based on dual role protein/PsaA as a pneumococcal vaccine. Eur J Pharm Sci. Elsevier; 2019;129:31-41.

682 20. Grenha A. Chitosan nanoparticles: A survey of preparation methods. J Drug Target. 2012;20:291300. al. Rational design of protamine nanocapsules as antigen delivery carriers. J Control Release. Elsevier B.V.; 2017;245:62-9. 22. Shen J, Burgess DJ. In vitro dissolution testing strategies for nanoparticulate drug delivery systems: recent developments and challenges. Drug Deliv Transl Res. 2013;3:409-15. whole blood. J Vis Exp. 2016;2016:2-7. 

immunomagnetic separation affects the morphology of monocyte-derived dendritic cells, as investigated by scanning electron microscopy. J Immunol Methods. Elsevier B.V.; 2016;439:79-82. murine dendritic cells (DCs) induced by thymic peptide: Pidotimod(PTD). Hum Vaccines Immunother. 2012;8:1250-8. biochemical and functional events associated with apoptosis and oncosis using the 7-aminoactinomycin D assay. J Immunol Methods. 2002;265:81-96. Immunother. 2016;12:383-92. studies. Crit Rev Microbiol. 2006;32:139-53. 30. Whaley MJ, Sampson JS, Johnson SE, Rajam G, Stinson-Parks A, Holder P, et al. Concomitant administration of recombinant PsaA and PCV7 reduces Streptococcus pneumoniae serotype 19A colonization in a murine model. Vaccine. Elsevier Ltd; 2010;28:3071-5.

31. Derksen JTP, Scherphof GL. An improved method for the covalent coupling of proteins to liposomes. BBA - Biomembr. 1985;814:151-5. nanoparticles for malaria antigen delivery and enhanced immunogenicity. PLoS One. 2017;12:1-19. characterization of helper T-cell epitopes from pneumococcal surface adhesin A. Immunology. 2014;141:514-30. chemistry facilitates metal ion release in the Psa permease. Nat Chem Biol. Nature Publishing Group; 

various applications. Des Monomers Polym. 2009;12:377-404. 36. Matsumoto M, Udomsinprasert W, Laengee P, Honsawek S, Patarakul K, Chirachanchai S. A WaterBased Chitosan-Maleimide Precursor for Bioconjugation: An Example of a Rapid Pathway for an In Situ Injectable Adhesive Gel. Macromol Rapid Commun. 2016;37:1618-22. 37. Martínez-Jothar L, Doulkeridou S, Schiffelers RM, Sastre Torano J, Oliveira S, van Nostrum CF, et al. Insights into maleimide-thiol conjugation chemistry: Conditions for efficient surface functionalization of nanoparticles for receptor targeting. J Control Release. Elsevier B.V; 2018;282:101-9. 38. Malhotra M, Tomaro-Duchesneau C, Saha S, Kahouli I, Prakash S. Development and characterization of chitosan-PEG-TAT nanoparticles for the intracellular delivery of siRNA. Int J Nanomedicine. 2013;8:2041-52. 39. Kumirska J, Czerwicka M, Kaczyński Z, Bychowska A, Brzozowski K, Thöming J, et al. Application of spectroscopic methods for structural analysis of chitin and chitosan. Mar Drugs. 2010;8:1567-636. 40. Esquivel R, Juárez J, Almada M, Ibarra J, Valdez MA. Synthesis and characterization of new thiolated chitosan nanoparticles obtained by ionic gelation method. Int J Polym Sci. 2015;2015. 41. Goulart C, Rodriguez D, Kanno AI, Silva JLSC, Leite LCC. Early pneumococcal clearance in mice induced by systemic immunization with recombinant BCG PspA-PdT prime and protein boost correlates with cellular and humoral immune response in bronchoalveolar fluids (BALF). Vaccine X. The Author(s); 2020;4:100049. 42. Alonso MJ. Nanomedicines for overcoming biological barriers. Biomed Pharmacother. 2004;58:16872.

43. Singh Y, Meher JG, Raval K, Khan FA, Chaurasia M, Jain NK, et al. Nanoemulsion: Concepts, development and applications in drug delivery. J Control Release. Elsevier B.V; 2017;252:28-49. nanocapsules: Physical characterization, stability in biological media and capsaicin encapsulation. Colloid Polym Sci. 2012;290:1423-34. 
45. Calvo P, Alonso MJ, Sur C. Development of positively charged colloidal drug carriers : chitosancoated polyester nanocapsules and submicron-emulsions. 1996; thiolated chitosan to preformed liposomes improves mucoadhesive properties. Int J Nanomedicine. $2012 ; 7: 2523-34$.

47. Maruyama CR, Guilger M, Pascoli M, Bileshy-José N, Abhilash PC, Fraceto LF, et al. Nanoparticles Based on Chitosan as Carriers for the Combined Herbicides Imazapic and Imazapyr. Sci Rep. Nature Publishing Group; 2016;6.

753 48. Shrestha S, Wang B, Dutta P. Nanoparticle processing: Understanding and controlling aggregation. Adv Colloid Interface Sci. Elsevier B.V.; 2020;279:102162.

755 49. González-Aramundiz JV, Peleteiro M, González-Fernández Á, Alonso MJ, Csaba NS. Protamine Nanocapsules for the Development of Thermostable Adjuvanted Nanovaccines. Mol Pharm.

757 2018;15:5653-64. 50. Tuoriniemi J, Johnsson ACJH, Holmberg JP, Gustafsson S, Gallego-Urrea JA, Olsson E, et al. Intermethod comparison of the particle size distributions of colloidal silica nanoparticles. Sci Technol Adv Mater. IOP Publishing; 2014;15. Chitosan determines its interactions with mucin. Biomacromolecules. 2014;15:3550-8. Fundamentals and applications. Biomimetics. 2019;4:1-20. 53. He F, Becker GW, Litowski JR, Narhi LO, Brems DN, Razinkov VI. High-throughput dynamic light scattering method for measuring viscosity of concentrated protein solutions. Anal Biochem. Elsevier Inc.; 2010;399:141-3. -oligo(NiPAam) polymeric micelles as novel drug nanocarriers. Nanomedicine. 2016;11:217-33. applications. Mar Drugs. 2015;13:1819-46. 

novel mucoadhesive materials for drug delivery. J Mater Chem B. 2016;4:6581-7. functionalised liposomes for drug delivery to urinary bladder. Eur J Pharm Sci. Elsevier B.V; 2018;111:83-90.

58. Tzankova V, Gorinova C, Kondeva-Burdina M, Simeonova R, Philipov S, Konstantinov S, et al. In vitro and in vivo toxicity evaluation of cationic PDMAEMA-PCL-PDMAEMA micelles as a carrier of curcumin. Food Chem Toxicol. Elsevier Ltd; 2016;97:1-10. 59. Mellman I, Steinman RM. Minireview Dendritic Cells: Specialized and Regulated Antigen Processing Machines cells are adept at endocytosis and express relatively low levels of surface MHC class I and II products and costimu-latory molecules (e.g., CD86). Abundant MHC class II mol-. Cell. 2001;106:255-8. 60. Banchereau J, Steinman RM. Dendritic cells and the control of immunity. Nature. 1998;392:245-52. 61. Al-Ashmawy GMZ. Dendritic Cell Subsets, Maturation and Function. Dendritic Cells. InTech; 2018. activity during dendritic-cell maturation. Blood. 2005;106:2375-81. tryptophan catabolism. Cell Death Differ. 2002;9:1069-77. Information about subscribing to The Journal of Immunology is online at : 2019; Infect Immun. 2009;77:568-75. 66. Dzopalic T, Rajkovic I, Dragicevic A, Colic M. The response of human dendritic cells to co-ligation of pattern-recognition receptors. Immunol Res. 2012;52:20-33. al. Polymeric nanocapsules for vaccine delivery: Influence of the polymeric shell on the interaction with the immune system. Front Immunol. 2018;9. 
